\title{
Specific carotenoid pigments in the diet and a bit of oxidative stress in the recipe for producing red carotenoid-based signals
}

\author{
Esther García-de Blas Alguacil ${ }^{1}$, Rafael Mateo ${ }^{2}$, Carlos Alonso-Alvarez ${ }^{\text {Corresp. }}{ }^{1,3}$ \\ 1 Instituto de Investigación en Recursos Cinegéticos (IREC), Universidad de Castilla La Mancha, Ciudad Real, Spain \\ 2 Instituto de Investigación en Recursos Cinegéticos (IREC), CSIC-UCLM-JCCM, Universidad de Castilla La Mancha, Ciudad Real, Spain \\ 3 Ecología Evolituva, Museo Nacional de Ciencias Naturales (MNCN), Consejo Superior de Investigaciones Científicas (CSIC), Madrid, Spain \\ Corresponding Author: Carlos Alonso-Alvarez \\ Email address: carlos.alonso@csic.es
}

Colorful ornaments have been the focus of sexual selection studies since the work of Darwin. Yellow to red coloration is often produced by carotenoid pigments. Different hypotheses have been formulated to explain the evolution of these traits as signals of individual quality. Many of these hypotheses involve the existence of a signal production cost. The carotenoids necessary for signaling can only be obtained from food. In this line, carotenoid-based signals could reveal an individual's capacity to find sufficient dietary pigments. However, the ingested carotenoids are often yellow and became transformed by the organism to produce pigments of more intense color (red ketocarotenoids). Biotransformation should involve oxidation reactions, although the exact mechanism is poorly known. We tested the hypothesis that carotenoid biotransformation could be costly because a certain level of oxidative stress is required to correctly perform the conversion. The carotenoid-based signals could thus reveal the efficiency of the owner in successfully managing this challenge. In a bird with ketocarotenoid-based ornaments (the red-legged partridge; Alectoris rufa), the availability of different carotenoids in the diet (i.e. astaxanthin, zeaxanthin and lutein) and oxidative stress were manipulated. The carotenoid composition was analyzed and quantified in the ornaments, blood, liver and fat. A number of oxidative stress biomarkers were also measured in the same tissues. First, we found that color and pigment levels in the ornaments depended on food levels of those carotenoids used as substrates in biotransformation. Second, we found that birds exposed to mild levels of a free radical generator (diquat) developed redder bills and deposited higher amounts of ketocarotenoids (astaxanthin) in ornaments. Moreover, the same diquat-exposed birds also showed a weaker resistance to hemolysis when their erythrocytes were exposed to free radicals, with females also enduring higher oxidative damage in plasma lipids. Thus, higher color production would be linked to higher oxidative 
stress, supporting the biotransformation hypothesis. The recent discovery of an avian oxygenase enzyme involved in converting yellow to red carotenoids may support our results. Nonetheless, the effect could also depend on the abundance of specific substrate carotenoids in the diet. Birds fed with proportionally higher levels of zeaxanthin showed the reddest ornaments with the highest astaxanthin concentrations. Moreover, these birds tended to show the strongest diquat-mediated effect. Therefore, in the evolution of carotenoid-based sexual signals, a biotransformation cost derived from maintaining a welladjusted redox machinery could coexist with a cost linked to carotenoid acquisition and allocation (i.e. a resource allocation trade-off). 
1

2

3

4

5

7

8

9

10

11

\title{
Specific carotenoid pigments in the diet and a bit of oxidative stress in the recipe for
} producing red carotenoid-based signals

\author{
García-de Blas, E ${ }^{1}$., Mateo, $\mathrm{R}^{1}$. \& Alonso-Alvarez, $\mathrm{C}^{1,2 *}$. \\ 'Instituto de Investigación en Recursos Cinegéticos (IREC, UCLM, CSIC), Ronda de Toledo sn, 13007 \\ Ciudad Real, Spain \\ ${ }^{2}$ Museo Nacional de Ciencias Naturales - CSIC. Dpto. Ecología Evolutiva. C/ José Gutiérrez Abascal 2, \\ 28006 Madrid, Spain \\ *Corresponding author: carlos.alonso@csic.es
}


13 Colorful ornaments have been the focus of sexual selection studies since the work of Darwin. Yellow to red coloration is often produced by carotenoid pigments. Different hypotheses have been formulated to explain the evolution of these traits as signals of individual quality. Many of these hypotheses involve the existence of a signal production cost. The carotenoids necessary for signaling can only be obtained from food. In this line, carotenoid-based signals could reveal an individual's capacity to find sufficient dietary pigments. However, the ingested carotenoids are often yellow and became transformed by the organism to produce pigments of more intense color (red ketocarotenoids). Biotransformation should involve oxidation reactions, although the exact mechanism is poorly known. We tested the hypothesis that carotenoid biotransformation could be costly because a certain level of oxidative stress is required to correctly perform the conversion. The carotenoid-based signals could thus reveal the efficiency of the owner in successfully managing this challenge. In a bird with ketocarotenoid-based ornaments (the redlegged partridge; Alectoris rufa), the availability of different carotenoids in the diet (i.e. astaxanthin, zeaxanthin and lutein) and oxidative stress were manipulated. The carotenoid composition was analyzed and quantified in the ornaments, blood, liver and fat. A number of oxidative stress biomarkers were also measured in the same tissues. First, we found that color and pigment levels in the ornaments depended on food levels of those carotenoids used as substrates in biotransformation. Second, we found that birds exposed to mild levels of a free radical generator (diquat) developed redder bills and deposited higher amounts of ketocarotenoids (astaxanthin) in ornaments. Moreover, the same diquat-exposed birds also showed a weaker resistance to hemolysis when their erythrocytes were exposed to free radicals, with females also enduring higher oxidative damage in plasma lipids. Thus, higher color production would be linked to higher oxidative stress, supporting the biotransformation hypothesis. The recent discovery of an avian oxygenase enzyme involved in converting yellow to red carotenoids may support our results. Nonetheless, the effect could also depend on the abundance of specific substrate carotenoids in the diet. Birds fed with proportionally higher levels of zeaxanthin showed the reddest ornaments with the highest astaxanthin concentrations. Moreover, these birds tended to show the strongest diquat-mediated effect. Therefore, in the evolution of carotenoid-based sexual signals, a biotransformation cost derived from maintaining 
42 a well-adjusted redox machinery could coexist with a cost linked to carotenoid acquisition and 43 allocation (i.e. a resource allocation trade-off).

44

45

46 


\section{Introduction}

Colored ornaments in animals have attracted the attention of evolutionary biologists since Charles Darwin, who suggested that most conspicuously colored traits are the product of sexual selection (Darwin 1871). Colored ornaments should provide some advantage when competing for a mate with same sex individuals (intrasexual selection) or by being more attractive to the choosing sex (intersexual selection; Andersson 1994). In many cases, colored traits inform competitors or potential mates about the quality of the owner. However, the trait should generate some benefit for both emitter and receptor to be considered as a signal (Hasson 1997; Bradbury \& Vehrenkamp 1998; Maynar Smith \& Harper 2003). This can occur by the transmission of information in a reliable (non-falsifiable) way (Maynard Smith \& Harper 2003).

In 1975, Amotz Zahavi proposed the "handicap principle", in which the reliability of the signal is due to its production/maintenance costs. The expression of a signal would proportionally be more costly for low-quality individuals compared to high-quality ones (Grafen 1990; also Getty 2006), the former being unable to signal or signaling in an inefficient way.

Carotenoids are natural pigments with immune-stimulant and antioxidant properties (Britton 2009) that are present in the integument of many vertebrate species, generating conspicuously colored traits (e.g. Brush 1990; Stradi 1998; McGraw 2006). The most obvious cost of carotenoid-based signals is the increase of conspicuousness that would raise the risk of predation (e.g. Godin \& McDonough 2003). This idea was suggested as early as Darwin (1871), regarding colorful ornaments but without citing the pigments.

The second cost associated with these traits is related to the fact that carotenoids cannot be synthesized de novo by the organism, but are only obtained from food (Britton 2009; McGraw 2006). Assuming that carotenoids are relatively scarce in food, colored individuals should pay a cost in terms of energy or time spent searching for pigments, which was suggested by Endler (1980, 1983) in fish studies (also Kodric-Brown 1985; see in birds Hill 1990; McGraw 2006). This hypothesis is difficult to test and has garnered mixed support, at least in avian species (reviewed in Hill 2006), which is probably the taxon where carotenoid-based signaling has been studied most in-depth (McGraw 2006; Pérez-Rodríguez 2009; Simons et al. 2012). Subsequently, Lozano (1994) was the first to emphasize the physiologically specific roles of carotenoids in an 
evolutionary context, suggesting that investing large amounts of pigment in signaling could compromise the immune system. This idea seems to be well supported at least for some inflammatory responses (phytohaemagglutinin skin test) in birds (reviewed in Simons et al. 2012). Subsequently, von Schantz et al. (1999) followed a similar reasoning but regarding the antioxidant properties of the pigments, proposing that investing in coloration would challenge the individual's capacity to combat oxidative stress. This type of stress is the result of an imbalance between the production of reactive oxygen and nitrogen species (RONS) by cell respiration and immune responses and the state (levels and efficiency) of the antioxidant defenses (Halliwell \& Gutteridge 2007). An evolutionary trade-off (Noordwijk \& De Jong 1986) in the investment of the carotenoid resources between self-maintenance (antioxidant defense) and reproduction (sexual signaling) could thus be established (Møller et al. 2000; AlonsoAlvarez et al. 2008). The von Schantz et al. (1999) hypothesis has gained popularity (e.g. Blount et al. 2003; Alonso-Alvarez et al. 2004; Hörak et al. 2007), probably because it unifies the physiological components of trait expression, since the immune response is at least partially regulated by the oxidative machinery (Halliwell \& Gutteridge 2007; Sorci \& Faivre 2009; Vallverdú-Coll et al. 2015).

Nonetheless, the antioxidant role of those carotenoids involved in sexual signaling has been questioned. This criticism has mostly arisen from the weakness of some correlations between carotenoid blood levels and certain measures of antioxidant capacity or oxidative damage in avian species (Costantini \& Møller 2008; Isaksson \& Andersson 2008). However, a meta-analysis on the published literature of this taxon seems to support the carotenoid antioxidant function, although the results were not robust (Simons et al. 2012).

Importantly, the carotenoid molecules giving color to the ornaments are frequently not the same as those carotenoids obtained from the diet and circulating in the blood (e.g. fishes: Hata \& Hata 1972; Ohkubo et al. 1999; birds: McGraw 2006 and references therein). This issue may be key to understanding the cost of the signal, but many obscure points are as yet not understood. In particular, the site (tissue) where carotenoids are transformed and the type of biochemical processes involved in such transformations are little understood. 
In avian species, the liver was the first tissue proposed as a potential biotransformation site (Brush \& Power 1976; Brush 1990) because it stores large amounts of carotenoids and it is the main 'laboratory' of the organism (Blem 2000; Britton 2009). Carotenoid biotransformation in the liver could compete with the activity of enzymes involved in detoxification (Blem 2000; Hill and Johnson 2012). Hence, the fact that this vital organ could be involved could affect our understanding of the costs derived from color production. Carotenoid transformation in the liver was supported by studies in crossbills (Loxia curvirostra), which found the pigment used for coloration in the liver and blood (del Val et al. 2009a,b; see also Hill y Johnson 2012). Studies in many other bird species, however, did not find this and instead suggested that the ornament is the main transforming site (McGraw 2004, 2009; García-de Blas et al. 2014), which would perhaps be less important for survival compared to the liver.

To understand how carotenoids are transformed we first need to know the biochemical route followed from substrate pigments to ornamental carotenoids, including the intermediate compounds (McGraw 2006; Britton 2009). Lutein and zeaxanthin are the most abundant carotenoids in the diet and blood of birds (McGraw 2006). Red ornaments displayed by many animal species are often the result of biotransformation of the cited yellow hydroxycarotenoids in red ketocarotenoids such as astaxanthin or canthaxanthin (McGraw 2006). The pathway followed from hydroxy- to ketocarotenoids requires hydrogenation and oxidation reactions. The existence in vertebrates of specific enzymes (hydroxylases and 4-oxygenases [i.e. ketolases]) was first proposed (McGraw 2006; Hill and Johnson 2012) and subsequently demonstrated in birds (see Lopes et al. 2016 and Mundy et al. 2016 describing a candidate oxygenase). In this regard, Hill and Johnson (2012; Johnson \& Hill 2013) have recently suggested that the oxidative status of the organism could influence the activity of these enzymes, with the carotenoid-based signals, in some way, revealing the individual's capacity to efficiently manage oxidative stress. The basic content of this idea was earlier formulated by Völker in 1957 when trying to explain why wild birds often lost their color in captivity. He proposed that this phenomenon is the result of impairment in the oxidative metabolism involved in carotenoid transformations. Although this could have deep implications for understanding the proximate costs of animal signaling, the hypothesis has not been experimentally tested until now. 
In the present study, the red-legged partridge (Alectoris rufa) was used as the model species. This gallinacean shows red ornaments (bill, eye rings, and legs) mostly produced by astaxanthin and papilioerythrinone ketocarotenoids (García-de Blas et al. 2013, 2014). We have experimentally shown that red head traits of males are used by females to adjust their reproductive investment, suggesting that these ornaments are indeed involved in sexual selection (Alonso-Alvarez et al. 2012). Experiments have also shown a relationship between integumentary coloration (and circulating carotenoid levels) and individual quality in terms of immune capacity (Pérez-Rodríguez and Viñuela 2008; Pérez-Rodríguez et al. 2008; Mougeot et al. 2009). Redder birds also show a better resistance to oxidative stress when exposed to an immune challenge (Pérez-Rodríguez et al. 2010). Moreover, young partridges exposed to high oxidative stress produced paler red traits and circulated lower blood carotenoid levels in adulthood (Alonso-Alvarez and Galván 2011). We have also described that astaxanthin and papilioerythrinone pigments are not present in blood, liver or fat, which indicates that pigment transformation takes place at the ornament site (García-de Blas et al. 2013, 2014 and 2015). We have proposed that astaxanthin and papilioerythrinone should be derived from zeaxanthin and lutein in food, respectively (i.e. García-de Blas et al. 2014), on the basis of published biochemical pathways (McGraw 2006; LaFountain et al. 2013). Lutein and zeaxanthin, in this order, are the most abundant carotenoids in the blood of this (García-de Blas et al. 2013) and many other bird species (McGraw 2006). As previously noted, the biotransformation of these compounds should involve oxidative reactions (McGraw 2006). Dietary lutein would be transformed to papilioerythrinone after one 4-oxidation and one dehydrogenation reactions, whereas dietary zeaxanthin would be converted into astaxanthin by two 4-oxidations (McGraw et al. 2006; LaFountain et al. 2013, García-de Blas et al, 2014).

Here, the carotenoid content of the diet of captive red-legged partridges was manipulated, subsequently exposing birds to an oxidative challenge. Our aims were (1) to reveal the metabolic pathway from dietary carotenoids to those deposited in the ornaments, (2) to verify the contribution to integument coloration of each dietary carotenoid, and (3) to determine if oxidative stress can influence color and the individual capacity to transform substrate carotenoids into those carotenoids allocated to ornaments. In this order, some birds received food supplemented with different zeaxanthin vs. lutein proportions, whereas other individuals received astaxanthin. In order to induce a higher oxidative stress, half of the birds in each 
164

165

166

167

168

169

170

171

172

173

174

175

176

177

178

179

180

181

182

183

184

185

186

187

188

189

treatment were also exposed to a free radical generator (diquat) in drinking water (Galvan \& Alonso-Alvarez 2009; see also Koch \& Hill 2016). We first predicted that a higher proportion of zeaxanthin in the diet should increase astaxanthin levels in ornaments whereas a higher proportion of lutein should instead raise the papilioerythrinone concentration. Since astaxanthin is the most abundant pigment in ornaments (García-de Blas et al. 2013, 2014), the group receiving dietary astaxanthin should a priori produce the reddest color and the highest astaxanthin concentrations in bare parts because no transformations would be required (Negro \& Garrido-Fernández, 2000). If transformations depend on specific enzymes inducing oxidative reactions, we can first predict that the oxidative challenge (higher availability of free radicals) could inhibit them by impairing/destabilizing the enzyme such as in the case of well-known antioxidant enzymes whose activity is decreased by high oxidative stress (e.g. glutathione synthase; Halliwell \& Gutteridge 2007). This would lead to paler birds with lower ketocarotenoid levels in ornaments. Alternatively, if the oxidative challenge is mild, these reactions could be favored in a sort of compensatory (hormetic) response (e.g. Costantini et al. 2010). This would lead to redder colors and higher ketocarotenoid levels in ornaments and specific transforming sites (i.e. liver; see above). We can only speculate on this mechanism as the nature of the ketolase enzymes is still poorly understood. Their activity should a priori depend on oxygen availability (Fraser et al. 1997; Schoefs et al. 2001). Superoxide or hydrogen peroxide generated by diquat redox cycling (Fussell et al. 2011; Koch \& Hill 2016) could perhaps provide this oxygen required for oxygenase activity and/or activate redox signaling pathways increasing enzyme transcription. In fact, superoxide and hydrogen peroxide can act as prime redox signaling molecules activating many different cell pathways (e.g. Hurd \& Murphy 2009). Nonetheless, free radicals derived from diquat redox cycling could also directly promote oxidation of dietary pigments. This last possibility should, however, imply increased ketocarotenoid levels in any body site where pigments and diquat-derived molecules interact (the blood should be the first site after absorption). 


\section{Material and Methods}

\subsection{Manipulation of carotenoid content in food}

In order to manipulate the carotenoid content of the diet, we collaborated with a company dedicated to producing animal pelleted feed (INALSA; Ciudad Real, Spain; http://www.piensosinalsa.com/contenido/perdices.htm; INALSA-UCLM agreement signed on May 25, 2012). We preferred to manipulate carotenoid levels in food because carotenoids diluted in drinking water (1) can directly pigment head traits due to splashing (previous observations in this and other species) and (2) would have interfered with our oxidative stress manipulation. We supplied a free radical generator (diquat; see below) in water. Carotenoids and diquat in the same solution would have reacted producing pro-oxidant carotenoid metabolites (e.g. El-Agamey and McGarvey, 2009). Alternatively, the use of two different water dispensers for each type of treatment would not have guaranteed a similar consumption of each solution.

The manipulation of carotenoid levels in the pellets was made on a basal commercial diet normally used during reproduction of captive red-legged partridges, containing wheat, barley, corn and soy in different proportions (INALSA, Spain). This feed did not contain any additional carotenoid to those naturally present in the grain, and it was mixed with the different commercial carotenoids resulting in the final feed. Commercial pigments used to prepare the different diets for the experiment were CROMO ORO Classic (min. lutein $16 \mathrm{~g} / \mathrm{Kg}$ and min. zeaxanthin 0.90 $\mathrm{g} / \mathrm{Kg}$ ), provided by DISPROQUIMA (Barcelona, Spain), OPTISHARPTM (Zeaxanthin 5\% CWS/S-TG), provided by DSM Nutritional Products (Switzerland) and CAROPHYLL ${ }^{\circledR}$ Pink (Astaxanthin 10\% CWS), provided by DSM Nutritional Products (Madrid, Spain). The adequate amounts of each pigment to add to the food were calculated taking into account the quantities of total carotenoids authorized for poultry feed (Directive 70/524/EEC, Communication 2004/C 50/01). Manipulation of carotenoid levels in the diet should resemble natural scenarios (Koch et al. 2016). However, the natural carotenoid content in the diet of wild red-legged partridges is currently unknown. We should, nonetheless, consider that body carotenoid levels of wild partridges are significantly higher than levels in captive birds that usually receive carotenoid supplements (Table 9S in García-de Blas et al. 2015). This suggests that our supplements would not produce unnatural phenotypes. Moreover, no negative effect due to a hypothetical 
220 pharmacological level was detected in terms of survival, body mass, reproductive output (egg

221 production) or oxidative stress levels (Results).

222

223

224

225

226

227

228

229

230

231

232

233

234

235

236

237

238

239

240

241

242

243

244

245

246

247

248

249

Pellets were elaborated following the habitual method of commercial feed preparation by using large-scale mills (Pietsch 2005). This process yielded perfectly homogeneous pellets, similar in size and color to base feed, avoiding the pigmentation of the head of the birds by direct contact. Diet 1 (Control) was the basal diet. Diets 2 and 3 contained lutein and zeaxanthin in different proportions: Diet 2 (called LutZea) contained approximately 73\% lutein and 27\% zeaxanthin, and diet 3 (ZeaLut) was formed by $52 \%$ lutein and 48\% zeaxanthin. Thus, diet 2 represented proportions often found in the natural diet of granivorous birds (McGraw 2006), whereas diet 3 was a diet enriched for zeaxanthin. Diet 4 was supplemented with astaxanthin (Ast). Carotenoid, tocopherol and retinol content of each type of pellet are shown in Table 1. Unexpected differences in tocopherol and retinol levels among treatments were found. This was probably due to the protective antioxidant action of carotenoids on vitamins present in the basal feed during the pelleting process, which involves high pressures and temperatures (Pietsch 2005), and to differences in the composition of supplements not detected during the formulation of each diet. Retinol and tocopherol are antioxidant vitamins involved in mutual recycling processes with carotenoids (Mortensen et al. 2001; Catoni et al. 2008; Surai et al. 2012). To discard the influence of this potential bias, tocopherol and retinol levels in every analyzed tissue (ornaments, plasma, liver and fat) were quantified and included as covariates in all statistical models (below).

\subsection{Experimental procedure}

The study was carried out at the Dehesa de Galiana experimental facilities (Instituto de Investigación en Recursos Cinegéticos and Diputación Provincial, Ciudad Real, Spain). The protocol was approved by the University of Castilla-La Mancha's Committee on Ethics and Animal Experimentation (approval number 1011.01). It was conducted on captive-born, oneyear-old red-legged partridges provided by a governmental breeding facility (Chinchilla, Albacete, Spain). We used 182 adult partridges forming 91 pairs that were kept in outdoor cages $(1 \times 0.5 \times 0.4 \mathrm{~m}$, each pair) under natural photoperiods and temperatures. No bird died during the study, but ten birds were removed from the experiment (and statistical analyses) due to escapes during handling (treatment groups did not differ in these exclusions, all $\chi^{2}, P>0.12$ ). In these 
250

251

252

253

254

255

256

257

258

259

260

261

262

263

264

265

266

267

268

cases, replacement birds were incorporated to keep pairs in similar conditions, but the new birds were not included in posterior samplings. The sex of individuals was determined genetically following Griffiths et al. (1998). Pairs were randomly divided into four groups that received one of the four diets. The sample size for Control, LutZea and ZeaLut groups was 23 pairs, and 22 pairs for the Ast group. Possible differences between groups in terms of food intake were checked during the experiment by weighing the pellet mass in feeders of a subsample of 10 pairs per group during one week, with no difference being detected (repeated-measures ANOVA; $F_{3,80}=0.732, p=0.536$ ). The experiment was carried out during the reproductive period (AprilJune), when the color expression of integuments is the greatest (Pérez-Rodríguez 2008).

On April 11 (“day 0"), a blood sample and a color measurement (below) of each ornament (eye ring, bill, and legs) from each partridge were taken in order to determine pretreatment color and blood levels of pigments and other physiological variables (below). Color measurements and blood samples were again taken on May 29 ("day 48”; intermediate sample). A third color and blood sampling was performed at the end of the experiment (July 2; "day 82"). One $\mathrm{mL}$ of blood was taken from the jugular vein, each time using heparinized syringes. Blood was centrifuged at $10,000 \times \mathrm{g}$ for $10 \mathrm{~min}$ at $4^{\circ} \mathrm{C}$ to separate plasma from the cell fraction. Both were stored separately at $-80{ }^{\circ} \mathrm{C}$ for later analysis. Before centrifugation, an aliquot of each blood sample was taken to calculate the hematocrit and resistance of erythrocytes against an oxidative challenge (see below).

On May 30, just after the second sampling, half of each treatment group ( $n=45$ pairs) were randomly allocated to the oxidative challenge. Of them, 11 pairs were from Control, ZeaLut, and Ast groups, and 12 pairs from the LutZea treatment. These birds were treated with diquat dibromide added to drinking water. The commercial product "Reglone" (Syngenta, Madrid) was used (20\% w/v of diquat dibromide in water). Diquat dibromide is a redox cycler that is transformed to a free radical which, in reaction with molecular oxygen, produces superoxide and other redox products (e.g. Sewalk et al. 2001; Zeman et al. 2005; Xu et al. 2007). The diquat bromide dose (i.e. $0.50 \mathrm{~mL} / \mathrm{L}$ Reglone in drinking water; Reglone contains $20 \% \mathrm{w} / \mathrm{v}$ of diquat dibromide in water) was established on the basis of a pilot study and the results obtained in previous work in the same species, which reported no body mass changes but 
279 increased lipid oxidative damage in erythrocytes (see Supporting Fig.1 in Alonso-Alvarez and 280 Galván, 2011; see also Galván \& Alonso-Alvarez 2009).

281

282

283

284

285

286

287

288

289

290

291

292

293

294

295

296

297

298

299

300

301

302

303

304

305

306

307

\subsection{Color measurements}

The coloration of eye-rings and bills of red-legged partridges was assessed by using a portable spectrophotometer (Minolta CM-2600D, Tokyo). Hue values were calculated by using the formula of Saks et al. (2003) for brightness (B) of different colors (i.e. hue $=\arctan \{[(B y-$ $\mathrm{Bb}) / \mathrm{BT}] /[(\mathrm{Br}-\mathrm{Bg}) / \mathrm{BT}]\}$, where yellow $[\mathrm{y}]$ is the addition of percentage reflectance within the $550-625 \mathrm{~nm}$ range, red $[\mathrm{r}]=625-700 \mathrm{~nm}$, blue $[\mathrm{b}]=400-475 \mathrm{~nm}$, green $[\mathrm{g}]=475-550 \mathrm{~nm}$ and $\mathrm{T}$ is total brightness). BT obtained from our spectrophotometer $(360-700 \mathrm{~nm})$ was added as a covariate to models testing the hue (see Statistical Analyses), since the original formula includes BT in both numerator and denominator, thus canceling out its effect. Repeatabilities of triplicate spectrophotometric measurements were significant for both traits $(r>0.68, P<0.001)$, with mean values for each sample being used.

Leg color was assessed by means of digital photographs (Nikon D-3100; see also Garcíade Blas et al. 2013) because the probe of our spectrophotometer did not adapt well to the leg surface (also Alonso-Alvarez \& Galván 2011). In this case, the birds were placed in the same position under standardized indoor light conditions (Kaiser Repro Lighting Unit; Repro Base with lights RB260 2x11W $6000^{\circ} \mathrm{K}$; Kaiser Fototechnik, Buchen) with the camera (Nikon D3100) always set to the same focus and conditions. A red color chip (Kodak NY) was placed close to the legs in order to control for subtle changes in environmental light, adding the hue values of the chip as a covariate to models testing leg color (Statistical analyses). Pictures were analyzed by a technician blind to the birds' identity. The color intensity of the central area of one of the tarsi was determined in adults by recording mean red, green and blue values (RGB system; e.g. Alonso-Alvarez et al. 2008) using Adobe Photoshop CS3. Hue was determined after conversion of RGB values by using the Foley and Van Dam (1984) algorithm. Repeatability of picture measurements taken twice from a different sample of red-legged partridges was high $(r>$ 0.90, $P<0.001, n=71$; Alonso-Alvarez \& Galvan 2011). Since lower hue values obtained from spectrophotometer measures or pictures indicated higher redness, the sign of the hue variables 
was reversed (multiplied by -1) to simplify interpretations. The term "redness" was thus used to describe the hue inverse.

\subsection{Quantification of carotenoids and vitamins}

The analyses of carotenoids, and vitamins $\mathrm{A}$ and $\mathrm{E}$ in internal tissues (i.e. plasma, liver, and subcutaneous fat) and colored integuments were performed by HPLC-DAD-FLD following the methods described by Rodríguez-Estival et al. (2010) and García-de Blas et al. (2011, 2013). Carotenoid levels are total values adding the levels of esterified and free forms for each specific pigment. Standards of lutein, zeaxanthin, canthaxanthin, astaxanthin, astaxanthin monopalmitate and astaxanthin dipalmitate were purchased from CaroteNature (Lupsingen, Switzerland). Retinyl acetate (used as an internal standard) and standards of retinol and $\alpha$-tocopherol were provided by Sigma-Aldrich. Carotenoid and vitamin concentrations were expressed as nmoles per gram of tissue.

\subsection{Resistance to hemolysis under free radical exposure}

The resistance of red blood cells to hemolysis under exposure to a free radical generator was assessed. Whole blood was exposed to a thermo-controlled free radical aggression by adding 2,2azobis-(aminodinopropane) hydrochloride (AAPH) (Rojas Wahl et al. 1998). Previous work has shown that if at least one component of the antiradical detoxification system is impaired, the hemolysis curve shows a shift towards shorter times (Blache and Prost 1992; Girard et al. 2005). This test, therefore, provides an assessment of resistance to oxidative stress because all families of free radical scavengers present in the blood are mobilized to fight off the oxidant attack (e.g. Blache and Prost 1992; Lesgards et al. 2002; Girard et al. 2005). Ten microliters of the blood of adult birds were immediately diluted and mixed with $365 \mu \mathrm{L}$ of KRL buffer (for $50 \mathrm{~mL}: 0.020 \mathrm{~g}$ of $\mathrm{KHCO}_{3} ; 0.0147 \mathrm{~g}$ of $\mathrm{CaCl}_{2} 2 \mathrm{H}_{2} \mathrm{O} ; 0.084 \mathrm{~g}$ of $\mathrm{NaHCO}_{3} ; 0.4036 \mathrm{~g}$ of $\mathrm{NaCl}, 0.00746 \mathrm{~g}$ of $\mathrm{KCl}$ in $50 \mathrm{~mL}$ mili-Q water, adjusting $\mathrm{pH}$ to 7.4 with $3 \mathrm{~N} \mathrm{HCl}$ ). The analyses were performed within 24 $\mathrm{h}$ following blood collection. Nonetheless, some aliquots could not be analyzed due to conservation problems, but this did not unbalance sample sizes of CAR and diquat treatments (all $\chi^{2}$ tests: $P>0.10$ ). Eighty microliters of KRL-diluted blood were incubated at $40{ }^{\circ} \mathrm{C}$ with $136 \mu \mathrm{L}$ of a $150 \mathrm{mM}$ solution of AAPH. The lysis of red blood cells was assessed with a microplate reader device (PowerWave XS2, Bio-Tek Instruments Inc., Winooski, VT), which measures the decrease in optical density at the wavelength of $540 \mathrm{~nm}$ every few minutes. Blood 
338 samples of a different bird species (zebra finch, Taeniopygia guttata) assessed twice were 339 repeatable $(r=0.84, P<0.001, n=43)$. Units are reported as minutes.

340

341

342

343

344

345

346

347

348

349

350

351

352

353

354

355

356

357

358

359

360

361

362

363

364

365

\subsection{Plasma antioxidants}

The total antioxidant status (TAS) of blood plasma was analyzed to estimate the availability of circulating hydrosoluble antioxidants. Since the idea that this measure assesses all the antioxidants is questionable, the term "total" was avoided, and hence, we will only use the generic "Plasma Antioxidants" (PLAOX). The procedure is based on Miller et al. (1993) modified by Cohen et al. (2007) and Romero-Haro and Alonso-Alvarez (2014). Repeatability calculated on other samples of red-legged partridges assessed twice was high $(r=0.94, P<$ 0.001, $n=20$; Galván \& Alonso-Alvarez 2009).

\subsection{Plasma biochemistry}

Albumin, uric acid, triglycerides, LDL-cholesterol and total cholesterol levels in plasma were determined with commercial kits (Biosystems SA, Barcelona, Spain) with an automated spectrophotometer (A25-Autoanalyzer; Biosystems SA, Barcelona, Spain). The last three parameters are components of lipoproteins that act as carotenoid carriers in blood (McGraw \& Parker 2006). They were assessed to test for differences in lipid absorption due to direct diquat effects on the gut (see also Alonso-Alvarez \& Galván 2011), but the diquat factor or its interaction with the CAR factor did not provide any significant influence on their levels (all $P$ values $>0.16)$.

\subsection{Lipid peroxidation}

The measurement of lipid peroxidation in plasma, liver and heart was carried out following the method described in Romero-Haro and Alonso-Alvarez (2014). Livers and hearts were previously diluted $(1: 10 \mathrm{w} / \mathrm{v})$ and were homogenized with a stock buffer (phosphate buffer 0.01 $\mathrm{M}$ adjusted to $\mathrm{pH} 7.4$ with $\mathrm{HCl} 37 \%$ ). Aliquots of $50 \mu \mathrm{L}$ of the samples (plasma, homogenized liver and heart samples, and standards) were then capped and vortexed for $5 \mathrm{sec}$, and were analyzed as described in Romero-Haro and Alonso-Alvarez, 2014. Zebra finch plasma samples assessed twice provided very high within-session $(r=0.97, n=20, P<0.001)$ and betweensession $(r=0.98, n=20, P<0.001)$ repeatabilities (Romero-Haro \& Alonso-Alvarez 2014). 


\subsection{Statistical analyses}

All the analyses were performed using SAS v9.3 software (SAS Institute 2006). The analyses are organized in two parts: (1) one testing the influence of carotenoid supplements only, and (2) the second analyzing the impact of the oxidative challenge (diquat exposure) and its interaction with carotenoid treatments.

The treatment effects on the number of birds producing eggs were calculated from contingency tables $\left(\chi^{2}\right)$. These analyses were separately performed for each experimental period (carotenoid exposure only or diquat exposure) and sex. Sex was considered because some females escaped during the experiment and hence sample sizes differed between sexes (see above). The variability in the number of eggs per individual was tested using a GENMOD procedure in the SAS software, including the number of eggs as a multinomial variable with cumulative logit link.

To test the carotenoid treatment (CAR hereafter) effect on color and blood variables throughout the study (i.e., three different measures), repeated-measures mixed models (PROC MIXED in SAS; Littell 2006) were used. In these models, the sampling event (TIME hereafter) was included as the repeated-measures factor, whereas the identity of the individual nested into cage identity was the subject term (REPEATED statement; Littell 2006). CAR (four-level factor), TIME (three-level factor) and sex were always included in the models as fixed effects, testing their two- and three-way interactions. Since the aim was exclusively testing the CAR effect with the highest available statistical power, these repeated-measure models did not include data from those individuals exposed to diquat (day 82 only).

To analyze the effect of diquat, variability at the last sampling (day 82) was analyzed by generalized mixed models (PROC MIXED in SAS). Here, CAR and diquat treatments and sex were tested as fixed factors, testing their interactions. Color and blood levels at the precedent sampling event (day 48) were tested as covariates to correct for subtle differences between groups at the start of the diquat exposure (section 3.3).

Other different covariates were added to the models. Thus, as previously mentioned, the redness (inverse of hue) of the eye ring and bill was controlled for total brightness. In the case of the leg, the redness of the red chip was tested. In all the repeated-measures mixed models testing 
the CAR effect, the influence of plasma vitamin (tocopherol and retinol) levels was tested by including them as covariates. In all the mixed models testing the diquat effect, plasma vitamin levels in the last sampling event, as well as vitamin levels in every internal tissue and ornaments, were also added. In models testing plasma MDA values, plasma triglyceride levels were added to control for potential influences of lipid variability in the blood (Romero-Haro \& Alonso-Alvarez 2014; Romero-Haro et al. 2015). In models testing PLAOX, uric acid, and albumin values were simultaneously tested to control for influences of recent food intake (Cohen et al. 2007). To control for subtle differences in reproductive investment, the number of eggs produced at the end of each sampling interval ("eggs") was also tested as a covariate in repeated models (Table 2). In models testing final variability (Tables 3 and 4), the total number of eggs at the end of the study or the number of eggs during only the diquat experiment were tested as alternative covariates (in different models). The lag time ( $\mathrm{min}$ ) to start hemolysis and hematocrit were added as covariates in models testing resistance to hemolysis. Finally, the identity of the bird nested into the identity of the cage and the laboratory session were included as random factors $(P$-values ranging from $<0.001$ to 0.476 ).

All the mixed models were explored from the saturated models. They firstly included all the covariates (although see alternative options above), fixed factors, and factor interactions. Alternative models were then tested by removing terms at $P>0.10$ by following a backwardstepwise procedure. The last best-fitted model was also compared to alternatives using the Akaike Information Criteria (AIC), providing similar conclusions. When tested as dependent variables, carotenoids and vitamins were transformed with mathematical functions to attain a normal distribution. All carotenoids and tocopherol levels were log-transformed, whereas vitamin A levels in the liver were transformed by a square root. In subcutaneous fat, carotenoid and retinol levels were standardized into two blocks because some sample sessions gave particularly low values. Differences are always provided as least square means $\pm \mathrm{SE}$ from models; that is, considering random factors and any term in the final model. Pair-wise comparisons were done by means of LSD post hocs. The description of interactions and their figures in the main text are restricted to tests reporting $P<0.10$. Other models, figures and tables containing means and SD from raw data are described in the Supporting Material. 
424

425

426

427

\section{Results}

\subsection{Egg laying}

The treatments did not affect the number of individuals producing eggs during the first (carotenoid supply only; all $\chi^{2}$ tests: $P>0.34$ ) or second (diquat $\times$ carotenoid supply interaction; all $\chi^{2}$ tests: $\left.P>0.86\right)$ part of the experiment. Similarly, the treatments did not influence the number of eggs produced during the first period (all $\chi^{2}$ tests: $P>0.65$ ) or the total number of eggs laid during the whole study (all $\chi^{2}$ tests: $P>0.11$ ). The addition of tocopherol or retinol values as covariates did not change any of these results. The tests on egg production reported similar results when including those males that were housed with new partners during the study (all tests: $P>0.10$ ).

\subsection{Influence of carotenoid supplements throughout the three sampling events}

Body mass was not affected by CAR treatments (time and sex interactions all $P>0.90$ ). In contrast, integument coloration changed throughout the study according to carotenoid supplements. Redness decreased throughout reproduction, but the LutZea and ZeaLut groups counteracted this effect (CAR $\times$ time interaction) in the eye ring and bill, although the latter trait only showed a trend toward significance (Table 2; Fig.1). In the eye ring, ZeaLut birds were redder than control and Ast partridges at the second sampling (both $P<0.05$; Fig. 1). On the last day, LutZea and ZeaLut groups showed redder eye rings than the other treatments $(P<0.034)$, but did not differ between them $(P=0.411$; Fig. 1$)$. In the bill, differences arose at the last sampling, with LutZea, ZeaLut (both $P<0.001$ ) and control (but $P=0.068$ ) birds redder than Ast animals. ZeaLut and LutZea birds were also redder than controls, with the latter only a trend ( $P=0.017$ and 0.064 , respectively; LutZea vs. ZeaLut: $P=0.673$; Table 2, Fig. $1 \mathrm{SM}$ ). The legs did not show a significant interaction (Table 2), although ZeaLut birds were redder than controls at the second and last samplings (both $P<0.013$; Fig. 1SM). 


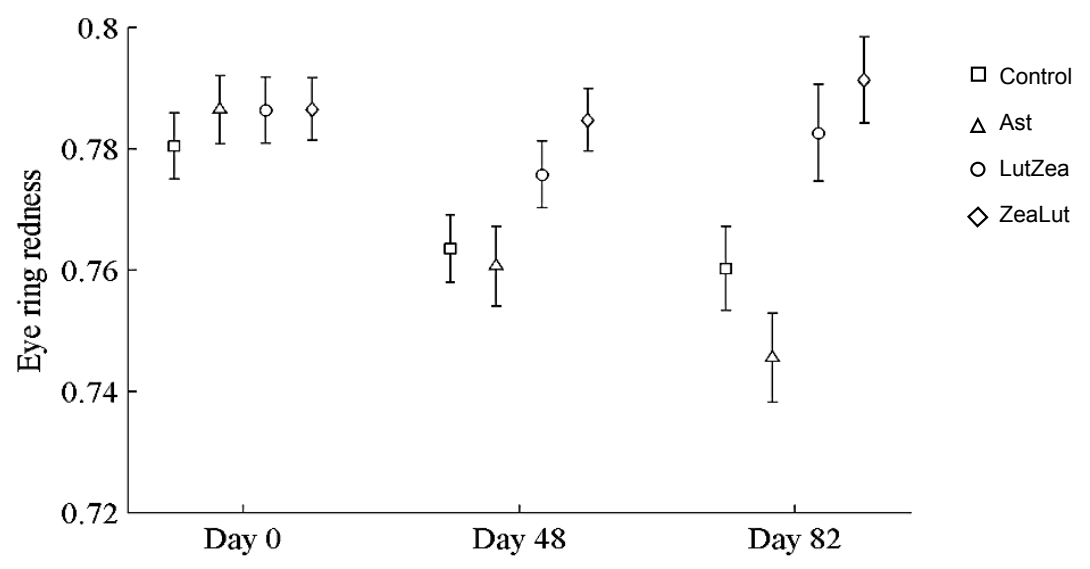

449

450

In terms of plasma pigments, the carotenoid treatment interacted with time (Table 2 and 452 Fig. 2). Lutein levels did not differ between ZeaLut and control birds at day $48(P=0.48)$, but 453 the other comparisons among groups on that day and at the last sampling were highly significant 454 (all $P<0.001$ ), with LutZea birds showing the highest values (Fig. 2). In the case of zeaxanthin, 455 only Ast and control birds did not differ at the last sampling $(P=0.730)$, with the other groups 456 differing clearly (all $P$-values $<0.001$ ). Agreeing with predictions, ZeaLut partridges showed the 457 highest zeaxanthin values (Fig. 2). 

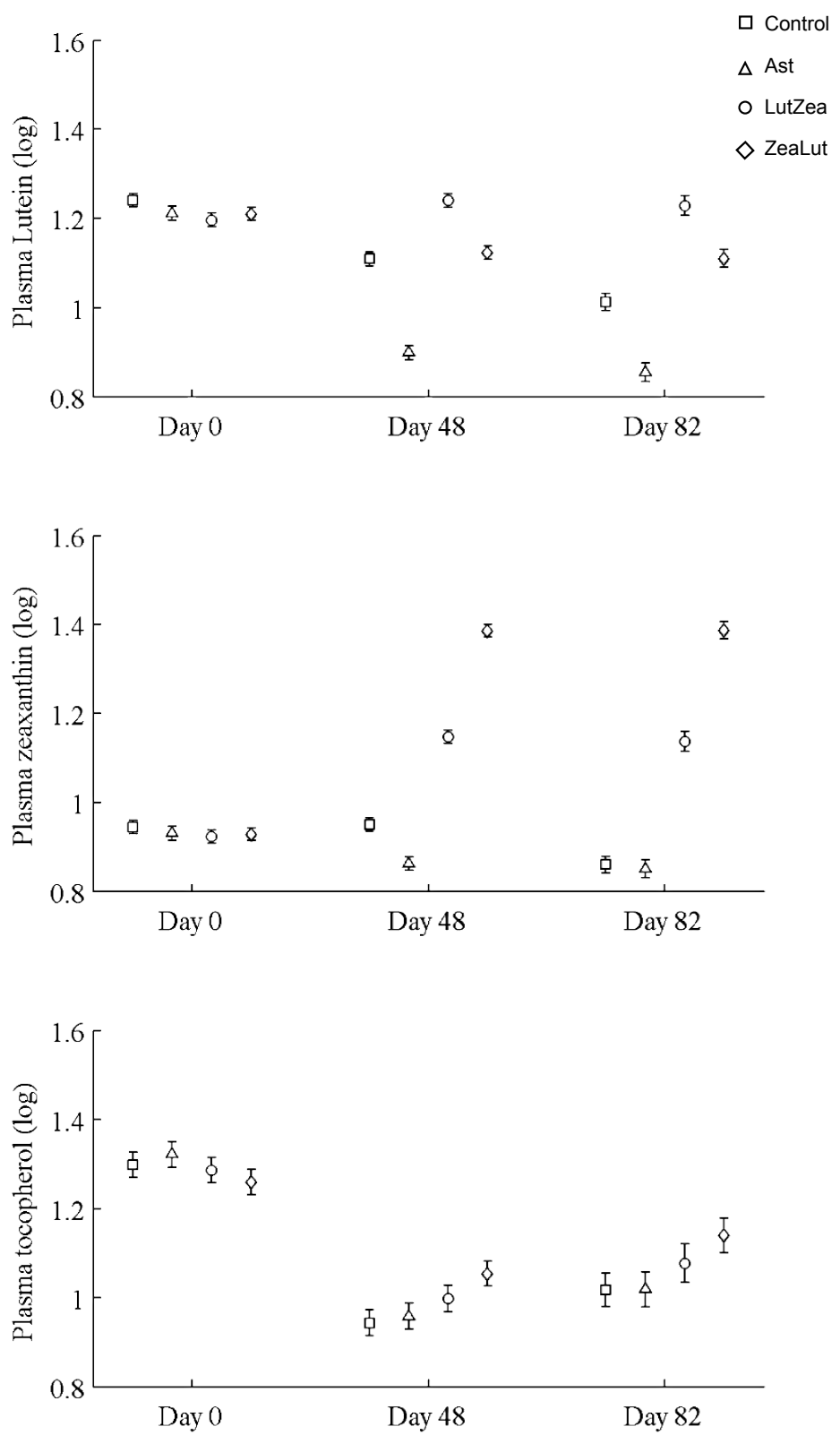

Figure 2. Changes in plasma carotenoids and tocopherol levels (log-transformed) during the experiment depending on the carotenoid treatment. Least squared means \pm se from the models (see Methods and Table 2).

Plasma vitamins used as covariates in these models (Table 2) were also tested as dependent variables. The CAR $\times$ time interaction was not significant for retinol but was for tocopherol (Table 2 and Fig. 2). ZeaLut birds showed higher tocopherol values than control and Ast individuals from 48 days to the end of the study (both $P<0.020$; other comparisons: $P>$ $0.13)$. 


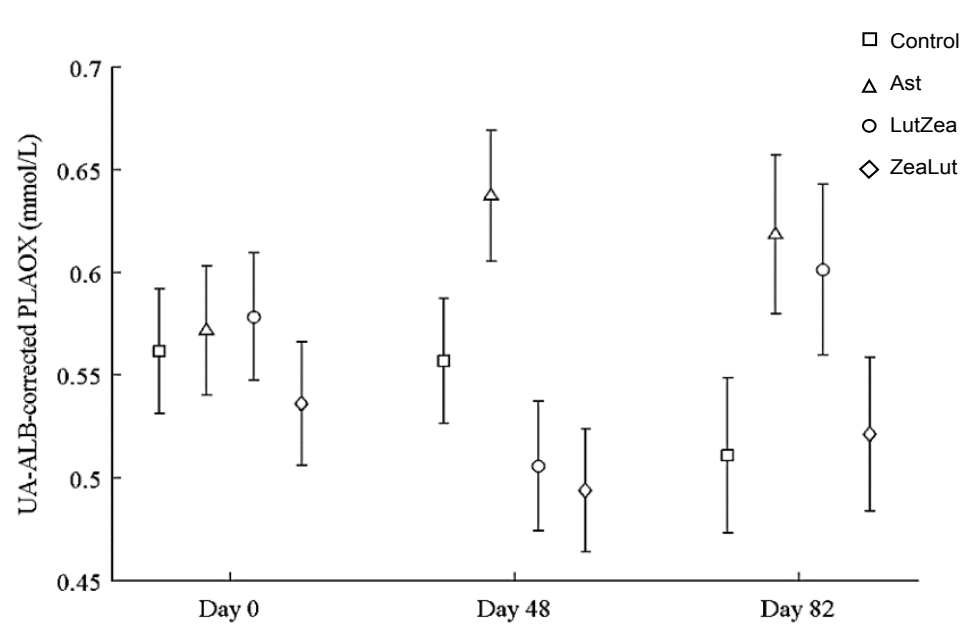

PLAOX changed according to the supplemented carotenoid (Table 2 and Fig. 3). On day 48, Ast showed higher values than other groups (all $P<0.012$ ), with controls reporting higher mean levels than ZeaLut $(P=0.034)$ and LutZea (but $P=0.098)$ birds. At the last sampling, LutZea birds increased their values approaching Ast individuals $(P=0.715)$. Ast birds again differed from the other two groups (both $P<0.023$ ), with LutZea animals showing a trend toward higher values than control $(P=0.052)$ and ZeaLut $(P=0.080)$ birds. The interaction remained $(P=0.020)$ when removing albumin and uric acid covariates (Fig. 3$)$.

Figure 3: Changes in the levels $(\mathrm{mmol} / \mathrm{L})$ of plasma antioxidant status (controlled for albumin and uric acid levels) during the experiment depending on the carotenoid treatment. Least squared means \pm se from the models (see Methods and Table 2).

472

473

474

475

476
Finally, plasma MDA (i.e., corrected or uncorrected for plasma lipid levels) and the resistance to oxidative stress in erythrocytes did not show significant differences with CAR during the study (all $P$-values $>0.64$; Table 2). 


\section{3.3. Variability after diquat exposure}

479 When testing variables at the end of the study (i.e. after diquat exposure), body mass controlled 480 for tarsus length variability was not influenced by CAR or diquat treatments or their interactions 481 (all $P>0.10$ ). The same was found for circulating LDL and total cholesterol levels (all $P>$ $4820.12)$.

483

484

485

486

487

488

489

490

491

492

493

\subsubsection{Ornament color and pigments}

In terms of redness, CAR did not clearly interact with diquat in any trait (all $P>0.24$; Table 3 and Fig. 2SM). Nonetheless, diquat-exposed birds showed marginally significant redder bills among control and ZeaLut birds $(P=0.051$ and 0.084 , respectively; Fig. 2SM). Moreover, in the eye ring model, sex showed a trend toward a significant interaction with diquat $(P=0.069$ in its last backward step). Males showed redder eye rings than females, but only among diquat-treated pairs (post hoc: $P=0.020$; diquat male: $0.770 \pm 0.006$; diquat female: $0.757 \pm 0.006$; control male: $0.762 \pm 0.006$; control female: $0.764 \pm 0.006$; other pairwise comparisons: $P>0.18$ ). In any event, in the best-fitted model excluding any interaction (i.e. Table 4), the diquat treatment alone reported a significant effect on bill redness, with diquat-treated birds showing redder bills (Fig. 4).

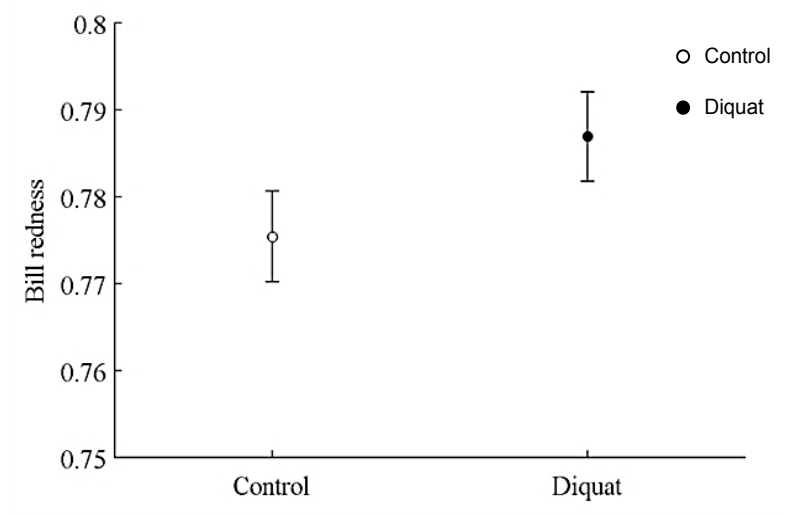

Figure 4. Effect of the diquat treatment on bill redness. Least squared means \pm se from the models (see Methods and 
495

496

497

498

499

Best-fitted models for any ornament also showed a strong CAR effect (all P-values < 0.001; Table 4). Ast birds were always the palest individuals (all $P<0.001$ ), whereas ZeaLut partridges were the reddest ones, followed by LutZea birds and controls (Fig. 5). Importantly, the difference in color between ZeaLut and LutZea animals was significant in eye rings and legs (both $P<0.044$; in the bill: $P=0.065$; Fig. 5).
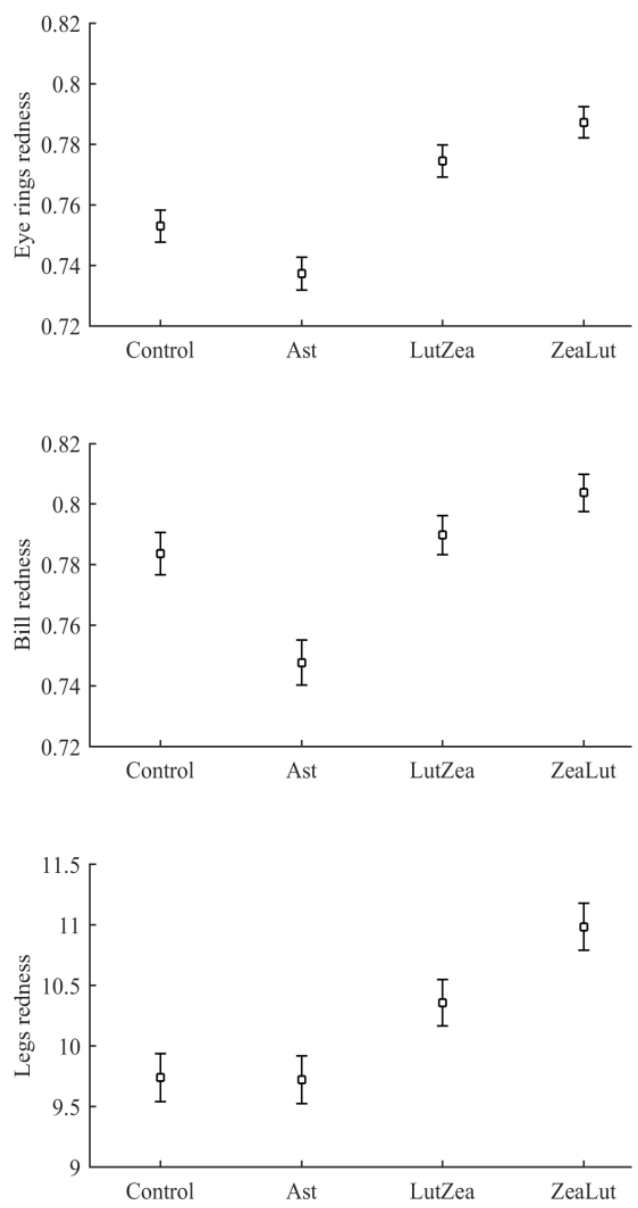

Figure 5. Final values of ornament coloration depending on carotenoid supplements exclusively. Least squared means \pm se from the models controlling for the diquat effect (Methods and Table 4).

Concerning pigments, neither lutein nor zeaxanthin was detected. Diquat affected astaxanthin levels in the eye ring and bill but depending on CAR (Table 3 and Fig. 6). The effect was partially due to differences in CAR-controls of both traits (both $P<0.020$ ), with diquat- 
506 treated birds showing higher astaxanthin concentrations. Nonetheless, in the eye rings ZeaLut 507 birds showed a marginally significant difference in the same direction $(P=0.057)$. In the same 508 eye ring and bill models, all pair-wise comparisons between carotenoid groups (CAR factor: both $509 P<0.001$ ) were significant (all $P<0.013$ ), showing increasing astaxanthin values in the 510 following order: Ast, control, LutZea and ZeaLut (Fig. 6). In legs, the diquat $\times$ CAR interaction 511 did not affect astaxanthin (Table 3). Only CAR remained in the model (Table 4), with LutZea 512 and ZeaLut birds showing higher astaxanthin levels (Fig. 3SM) than other groups (all $P<0.025)$, 513 but not differing between them $(P=0.162$; also Ast vs. control: $P=0.248)$.
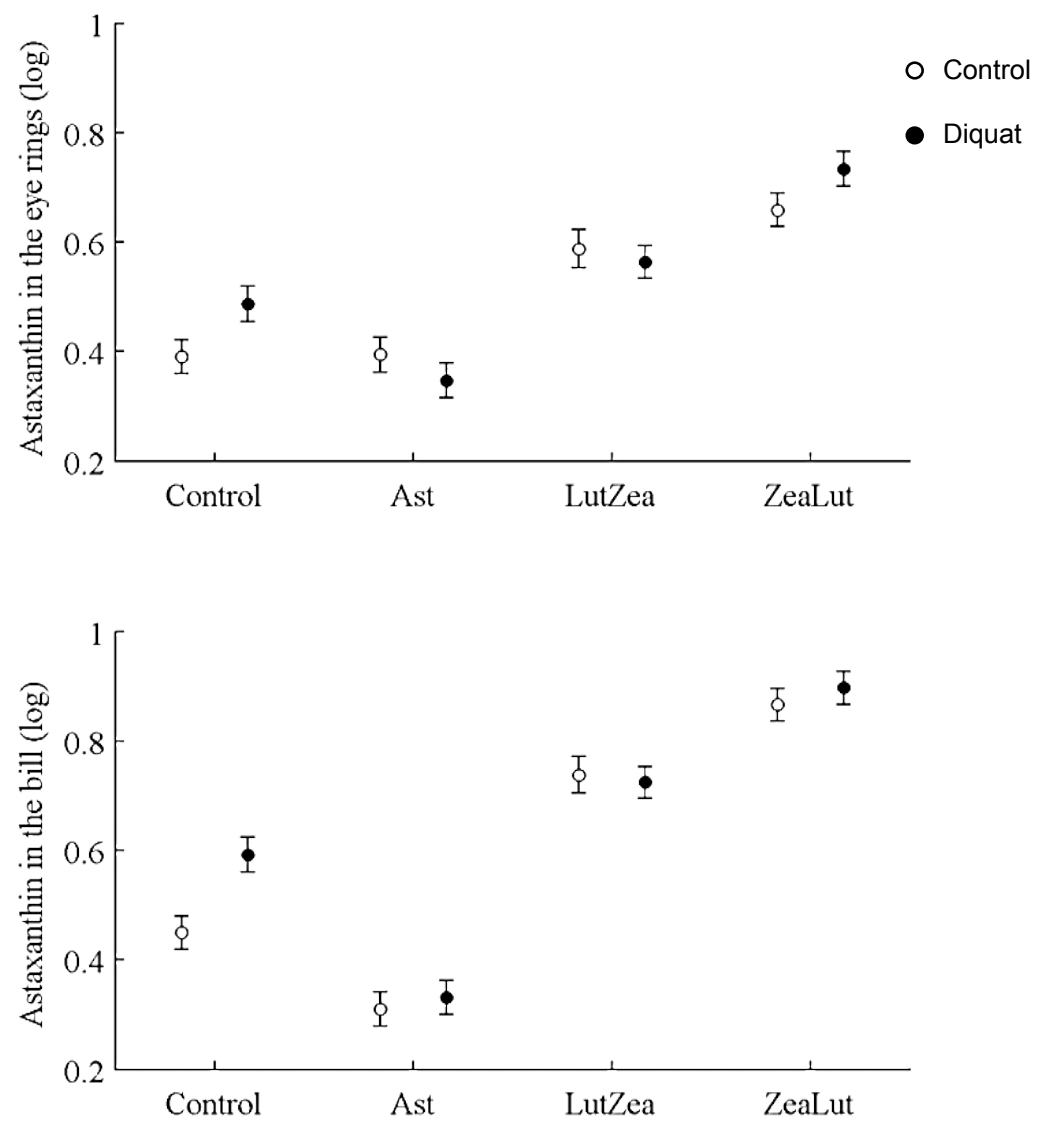

Figure 6. Levels of astaxanthin in the eye rings and in the bill after diquat exposure depending on the carotenoid treatment. Least squared means \pm se from the models (see Methods and Table 3).

In contrast to astaxanthin, papilioerythrinone was unaffected by diquat (any trait: $P>$ 0.16; Table 3). The best-fitted model (Table 4) always reported a significant CAR influence (all traits: $P<0.010$; Fig. 4SM). In the eye rings, LutZea and ZeaLut birds did not differ $(P=0.526)$, 
518 but other comparisons were significant $(P<0.012)$. In the bill, all CAR groups differed $(P<$ 519 0.009), with LutZea showing higher levels than ZeaLut, and Ast showing the lowest values. In 520 the legs, LutZea presented higher papilioerythrinone levels than other groups (all $P$ 's $<0.017$; 521 differences among other groups $P>0.13$; Fig. 4SM).

522 Tocopherol and retinol are antioxidant vitamins whose variability could indirectly 523 influence carotenoid values (although tested as covariates in the models; see Methods). 524 Tocopherol, but not retinol, was detected in the ornaments. In the eye ring, the diquat $\times$ CAR 525 interaction showed a trend toward significance $(P=0.056)$, with diquat decreasing tocopherol 526 values in controls only $(P=0.021$; Tables 3 and 2SM for raw data; see also Fig. 7$)$. In the same 527 model, the CAR factor $(P=0.017)$ showed that ZeaLut partridges had higher tocopherol levels 528 than LutZea and control birds (both $P<0.016$ ), but Ast birds also showed higher vitamin levels
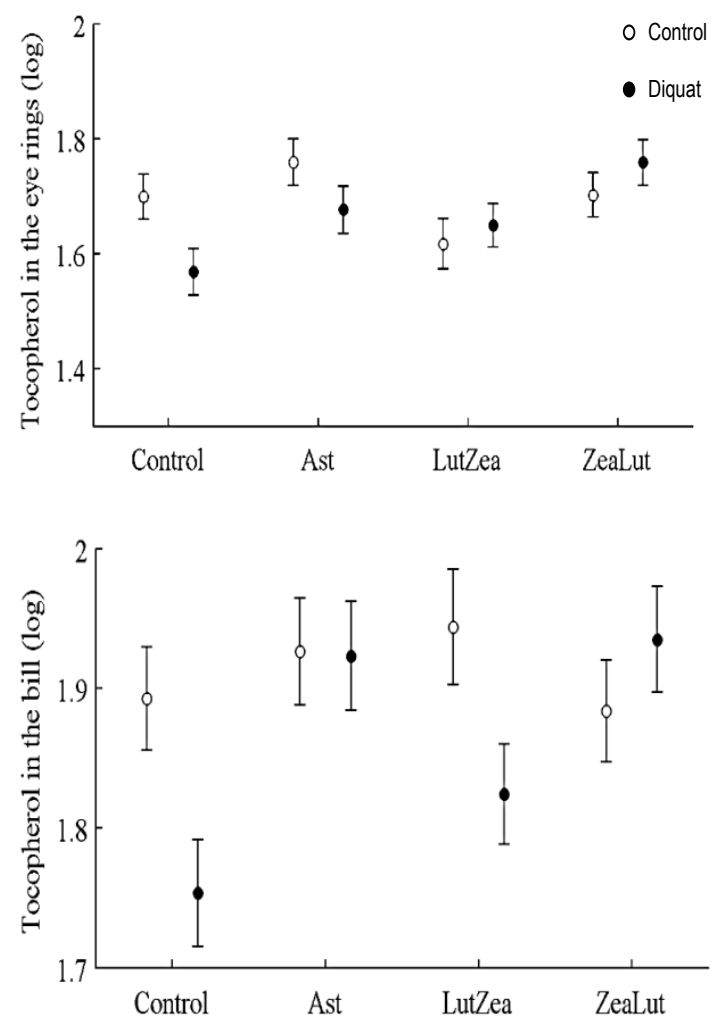

Figure 7. Levels of tocopherol in the eye rings and bill after diquat exposure depending on the carotenoid treatment. Least squared means \pm se were obtained from the models (see Methods and Table 3).

529 than LutZea and control animals (both $P<0.039$; other comparisons $P>0.75$ ). 
In the bill, tocopherol was also affected by diquat $\times$ CAR (Table 3 and Fig. 7). Diquat decreased tocopherol values in control and LutZea individuals (both $P<0.05$; Fig. 7). The CAR factor $(P=0.035)$ only indicated that controls had lower values than Ast and ZeaLut (both $P<$ 534 0.020). Finally, only the CAR effect was significant in the legs (Tables 3 and 4). ZeaLut birds 535 showed the highest tocopherol concentrations in the legs (both $P<0.005$ when compared to 536 LutZea and controls; $P=0.085$ when compared to Ast).

537

538

539

540

541

542

543 544

\subsubsection{Plasma and internal tissues}

With regard to circulating carotenoids, lutein showed a significant diquat $\times$ CAR interaction (Table 3). Among CAR groups, only controls showed significantly higher lutein levels with diquat $(P=0.039$; control: $0.98 \pm 0.01$; diquat: $1.02 \pm 0.01, \log$-values; Fig. 8$)$. In the case of zeaxanthin, although the CAR $\times$ diquat interaction was non-significant $(P=0.200$; Table 3$)$, the post hoc comparison within the control-CAR group showed a similar diquat effect $(P=0.033$; control: $0.86 \pm 0.02$; diquat: $0.91 \pm 0.02$; Fig. 8 ). No other pigment showed detectable levels in plasma. 

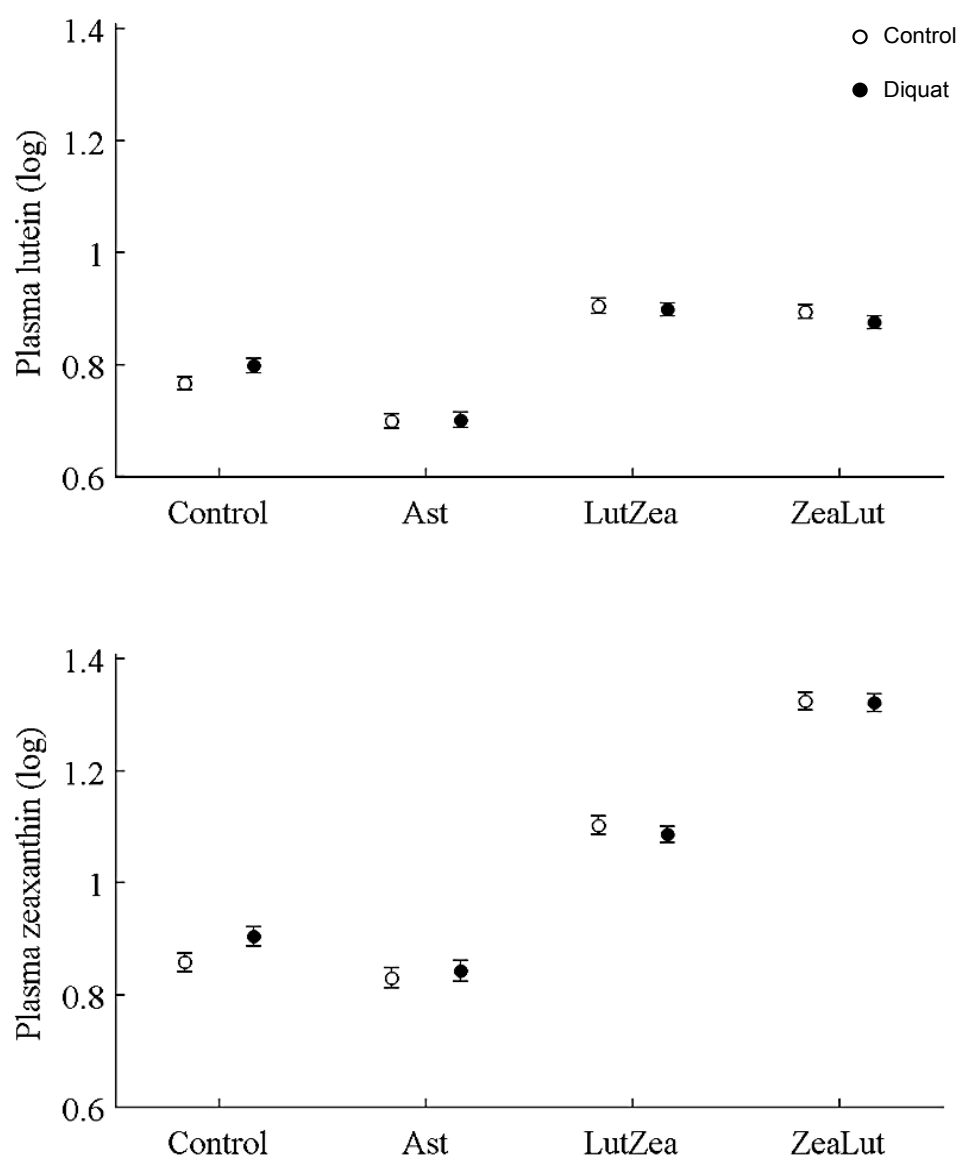

Figure 8. Levels of lutein and zeaxanthin in plasma after diquat exposure depending on the carotenoid treatment. Least squared means \pm se were obtained from the models (see Methods and Table 3).

545

546

547

548

549

550

551

552

553

554

With regard to plasma vitamins, tocopherol was unaffected by the diquat $\times$ CAR interaction (Table 3). Nonetheless, diquat showed a significant effect (Table 4), with tocopherol values decreasing after the exposure (control: $1.08 \pm 0.02$; diquat: $1.03 \pm 0.02$ ). No factor or interaction was significant in the case of plasma retinol (all $P>0.10$; Table 4).

In the liver, the diquat $\times$ CAR interaction did not affect lutein levels (Table 3 ). The bestfitted model reported a strong significant CAR effect (Table 4). LutZea and ZeaLut birds did not differ $(P=0.103)$ and showed the highest lutein levels (Fig. 5SM). The other comparisons always reported $P<0.001$, and the Ast group showed the lowest value (Table 3SM). In contrast, liver zeaxanthin showed a significant CAR $\times$ diquat interaction (Table 3 ). This effect was mostly 
555 due to diquat reducing zeaxanthin levels in ZeaLut birds $(P=0.028)$, and a trend in the opposite 556 direction among controls $(P=0.064$; Fig. 9). Importantly, such as in the case of astaxanthin in 557 ornaments, the CAR factor $(P<0.001)$ reported increasing liver zeaxanthin values in the 558 following order: Ast, control, LutZea and ZeaLut (all comparisons: $P<0.040$ ).

559

560

561

562

563

564

565

566

567

568

569

570

571

572

573

574

68

69

70
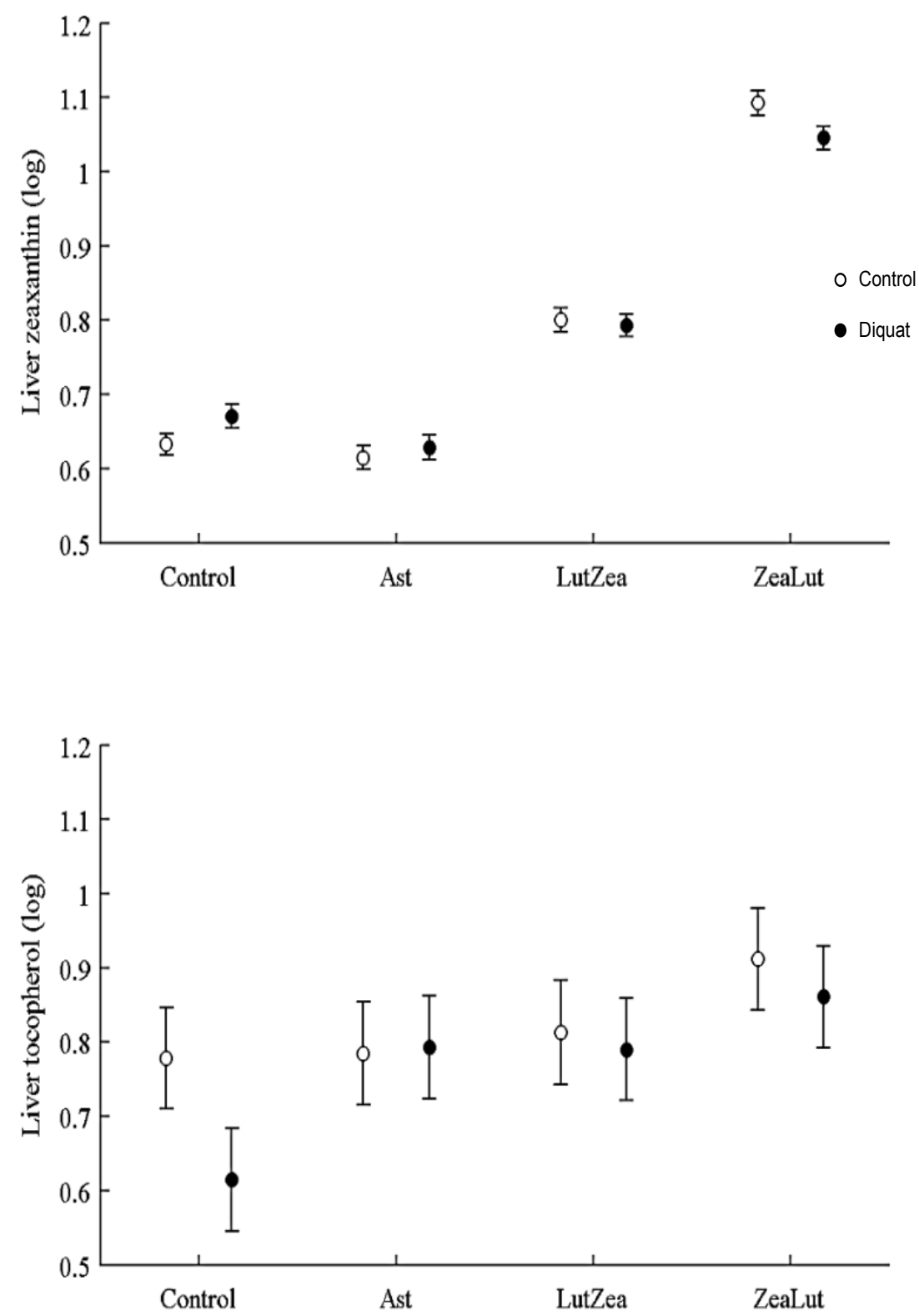

Figure 9. Levels of zeaxanthin and tocopherol in the liver after diquat exposure depending on the carotenoid treatment. Least squared means \pm se were obtained from the models (see Methods and table 3). 
With regard to liver vitamins, tocopherol was affected by CAR $\times$ diquat (Table 3 ). 577 Among CAR groups, only control values showed a diquat effect on tocopherol, i.e. a decline $(P$ $578=0.001$; Fig. 9). The CAR factor in the same model $(P<0.001)$ indicated significant differences 579 following the order showed above for liver zeaxanthin (all $P<0.003$ ), but here control and Ast 580 birds did not differ $(P=0.699)$. In the case of liver retinol, both free and esterified retinol forms were detected, the two values being added for analyses (i.e. vitamin A). This variable was unaffected by CAR $\times$ diquat (Table 3 ) but showed a significant CAR effect (Table 4). LutZea and ZeaLut birds did not differ $(P=0.133)$, with Ast animals reporting the highest level, and control birds the lowest (other $P<0.001$; Fig. 5SM).

In the subcutaneous fat, no carotenoid or vitamin was affected by $\mathrm{CAR} \times$ diquat (all $P$ values $>0.80$; Table 3 ). The best-fitted models always reported a significant CAR effect (Table

\subsubsection{Oxidative stress biomarkers}

PLAOX showed a three-way CAR $\times$ diquat $\times$ sex interaction (Table 3; Fig. 10). Diquat decreased hydrosoluble antioxidant levels in LutZea males $(P=0.02)$, showing a trend in the same direction in females, but in the ZeaLut group $(P=0.06$; Fig. 10). No factor or interaction remained (all $P>0.18$ ) when removing uric acid and albumin covariates (though they showed $P$ 602 $<0.057)$. 

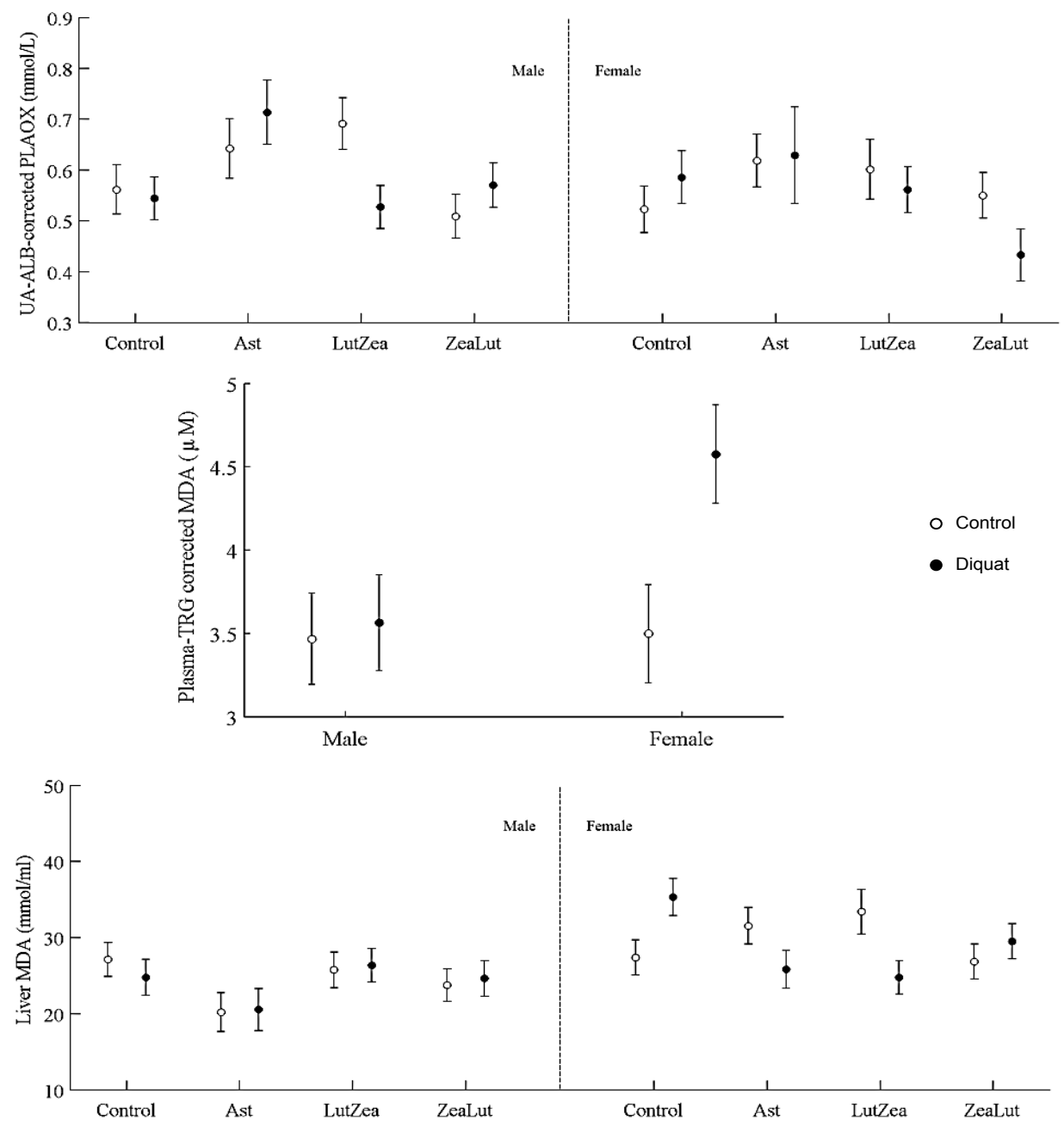

Figure 10. Levels of oxidative stress biomarkers after diquat exposure depending on the carotenoid treatment. Least squared means \pm se from the models (see Methods and Table 3).

603

604

605

606

607

608

609

610

611

In plasma MDA, CAR $\times$ diquat was non-significant $(P=0.466$; Table 3$)$, but diquat $\times$ sex interacted (Table 4; Fig. 10). Diquat-treated females showed higher lipid peroxidation than control females $(P=0.001$; males did not differ: $P=0.752)$. The interaction did not change $(P=$ 0.008) when removing the triglyceride covariate. The CAR group was never significant $(P>$ 0.5). In liver MDA, the three-way interaction again arose (Table 3; Fig. 10). Diquat increased MDA values in control females $(P=0.009)$, but decreased MDA in LutZea $(P=0.014)$ and Ast (but at $P=0.079$ ) females. Moreover, diquat control-CAR females also tended to endure higher liver MDA values than diquat ZeaLut females $(P=0.068)$. No difference was found in males (all 
$612 P>0.10)$. The CAR group in the model was not significant $(P=0.289)$. No factor or interaction 613 reported significant terms in heart MDA (Table 4; all $P>0.12$ ).

614

615 616 617 significant (all $P>0.50)$.

Figure 11. Effect of the diquat treatment on the erythrocyte resistance to oxidative stress. Least squared means \pm se from the models (see Methods and Table 4).

618

619

620

621

622

623

624

625

626

627

628

629

\section{8}

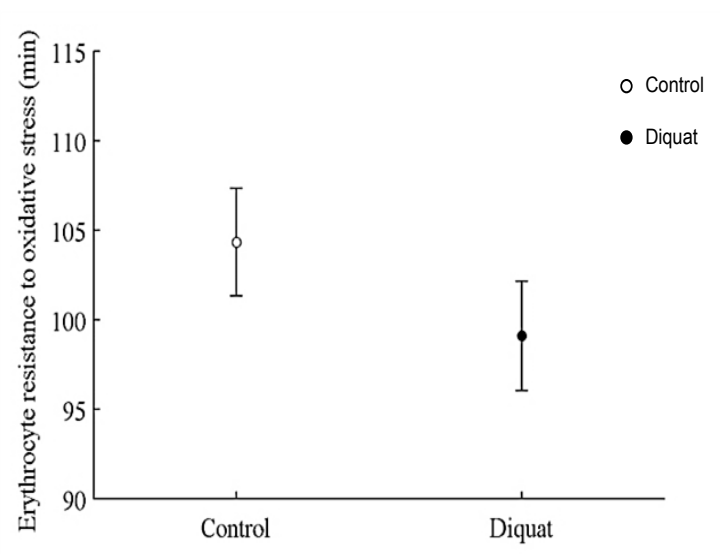

Finally, in the case of erythrocyte resistance to oxidative stress, the CAR $\times$ diquat interaction only showed a weak trend toward significance $(P=0.090$; Table 3$)$, but the bestfitted model reported a significant diquat effect (Table 4; Fig. 11). The CAR factor was not

\section{Discussion}

Our results as a whole suggest that the availability of certain carotenoids in the diet and the level of oxidative stress can coexist and interact to produce pigmentation in avian ornaments. As predicted, a higher dietary content of lutein vs. zeaxanthin (LutZea) led to a higher papilioerythrinone accumulation in the red ornaments, whereas the opposite (ZeaLut) led to a higher astaxanthin deposition. Birds fed with higher zeaxanthin and lutein proportions showed the reddest ornaments, but the first (ZeaLut) showed the reddest traits (eye rings and legs) at the end of the study. Furthermore, the oxidative challenge produced redder bills and higher astaxanthin deposition in the bare parts of some birds, the latter depending on tocopherol levels in the same tissue. 
630

631

632

633

634

635

636

637

638

639

640

641

642

643

644

645

646

647

648

649

650

651

652

653

654

655

656

657

658

\subsection{Covariation between vitamins and carotenoids}

The carotenoid treatments affected tocopherol levels in tissues. However, this only partially agreed with diet composition, which showed the highest vitamin values in the ZeaLut and, particularly, the Ast groups (Table 1). In legs, plasma and liver, only ZeaLut birds showed higher tocopherol levels than other groups. The lack of high tocopherol values in Ast partridges in these tissues could be explained by astaxanthin interfering with vitamin absorption (e.g. Giraudeau et al. 2013; also below). Nonetheless, both Ast and ZeaLut groups showed the highest tocopherol levels in the other ornaments. In the case of retinoids, Ast birds also showed the highest value in liver and fat, but ZeaLut and LutZea groups did not differ.

Results also suggest that carotenoids protected vitamin E from oxidative stress. In the bill, eye rings, and liver, diquat decreased tocopherol levels, but only among birds that did not receive carotenoid supplements. This suggests that a higher carotenoid availability among CARtreated birds buffered tocopherol consumption due to free radicals, which supports the idea of mutual recycling and protective roles between tocopherol and carotenoids (Mortensen et al. 2001; Catoni et al. 2008; Surai et al. 2012). The only exception was the diquat-mediated reduction in tocopherol levels in the bill of LutZea birds. Regardless, we must consider that, among carotenoids, lutein (i.e. the most abundant carotenoid in LutZea birds) is the weakest antioxidant (Britton 1995; Martínez et al. 2008; see also below).

To discriminate carotenoid effects from the influence of vitamin variability in the diet, all the statistical models were controlled for tocopherol and retinoid levels in the tissues. The problem of collateral variation of antioxidants in a supplemented diet has mostly been ignored in experiments aiming to strictly manipulate dietary carotenoid levels. For instance, Stirnemann et al. (2009) and Toomey \& McGraw $(2011,2012)$ have used the same beadlets including zeaxanthin and tocopherol, but vitamin levels were not considered in their analyses. The addition of other antioxidants as excipients in carotenoid supplements would protect carotenoids during storage. In the other direction, the addition of carotenoids to the pelleted food could also have protected antioxidant vitamins in the basal diet, thus disrupting the original covariation among the levels of different compounds (Table 2; Catoni et al. 2008). In any event, we must note that diquat effects within a particular carotenoid treatment were independent of vitamin variability in 
659 that group as both diquat and control birds should have received the same vitamin amounts. In

660

661

662

663

664

665

666

667

668

669

670

671

672

673

674

675

676

677

678

679

680

681

682

683

684

685

686

687

688 summary, results must be carefully interpreted in the light of vitamin covariation.

\subsection{Metabolic pathway of dietary carotenoids}

We predicted that birds supplemented with astaxanthin should produce the most pigmented ornaments as biotransformation is not required. Surprisingly, dietary astaxanthin was apparently not absorbed. It was not detected in blood and other internal tissues. Moreover, astaxanthin seems to have interfered with lutein, zeaxanthin and tocopherol acquisition, as the circulating levels of these molecules declined in Ast birds. Consequently, ketocarotenoid deposition in ornaments and trait redness were reduced. Carotenoid competition during intestinal absorption and/or incorporation into the chylomicrons (e.g. Tyssandier et al. 2002; Canene-Adams and Erdman Jr. 2009) can be argued considering the literature on humans (reviewed in Furr and Clark, 1997; van der Berg 1999). In birds, competitive interactions of beta-carotene vs. lutein or zeaxanthin during intestinal absorption have also been reported for poultry diets (Wang et al. 2010). Interestingly, in the opposite direction, flamingoes (Phoenicopterus ruber) fed with lutein or zeaxanthin were unable to absorb these two pigments, but were instead able to assimilate astaxanthin, which is used as a precursor for the main carotenoid in their feathers (i.e. canthaxanthin; Fox and McBeth, 1970; McGraw 2006). Our partridges also differ from European storks (Ciconia ciconia) naturally feeding on crayfish (Procambarus clarkii) containing high astaxanthin concentrations because they showed redder skin and higher astaxanthin concentrations in blood than controls (Negro and Garrido-Fernández, 2000). Phylogenetic differences may explain this. Astaxanthin is common in waterbirds feeding on fishes and aquatic invertebrates (an important astaxanthin source), but not among other avian species (McGraw 2006). The red-legged partridge is a terrestrial granivorous gallinacean, and thus, astaxanthin is probably infrequent in their natural diet. For this reason, the capacity for assimilating astaxanthin may not have evolved. Nonetheless, other granivorous (but passerine) birds are able to absorb canthaxanthin (McGraw \& Hill 2001; Hill 2002), another carotenoid described in aquatic organisms (McGraw 2006).

On the other hand, our manipulation mostly supports the biotransformation pathway proposed for red-legged partridge carotenoids (i.e. García-de Blas et al. 2014); that is, lutein 
689

690

691

692

693

694

695

696

697

698

699

700

701

702

703

704

705

706

707

708

709

710

711

712

713

714

715

716

717

718

acting as the main papilioerythrinone precursor, with zeaxanthin acting as the main astaxanthin substrate. Lutein and zeaxanthin levels rose in the blood, liver and fat according to their relative abundance in the diet. Similarly, papilioerythrinone and astaxanthin in ornaments increased in higher amounts in LutZea and ZeaLut groups, respectively. The results support previous correlative findings in the same species (García-de Blas et al. 2015) and demonstrate that the ketocarotenoids giving color to red-legged partridge ornaments are influenced by the availability of the most common hydroxycarotenoids in birds (McGraw 2006). As previously mentioned, lutein and zeaxanthin are the most frequently described and abundant carotenoids in the food and blood of many bird species, as well as the most common substrates for red ketocarotenoids in ornaments, at least among non-aquatic species (Surai et al. 2001; McGraw 2006). In passerines, lutein levels always prevail over zeaxanthin levels in both blood and diet, commonly at a 70:30 ratio (lutein:zeaxanthin) or higher (e.g. McGraw et al. 2004), which could also reflect the dietary content (McGraw 2006). Our manipulation supports this for a gallinacean species. Moreover, McGraw et al. (2004) proposed that birds should prioritize zeaxanthin accumulation because this pigment would proportionally contribute more to coloring red ornaments compared to lutein. This has only been supported by correlations between the ratio of these two principal hydroxycarotenoids in the body and the ratio of pigments deposited in the ornaments (McGraw and Gregory 2004; García-de Blas et al. 2015). Our experimental results also confirm this, and support, to some extent, the hypothesis that carotenoid-based signaling reveals an individual's capacity to find specific carotenoids in the environment (Hill 1994, 2002).

Finally, the fact that astaxanthin and papilioerythrinone were only found in bare parts validates our previous findings (Garcia-de Blas et al. 2015) and again supports the idea that biotransformation can take place in situ, at the colored trait, something only explored and described in passerines (McGraw 2004, 2009 for eleven species; but see Del Val et al. 2009 and McGraw and Toomey 2010 for two other passerine species). The two recent studies describing a candidate oxygenase for carotenoid biotransformation have detected the enzyme in both the liver and feather follicles of canaries (Serinus canaria; Lopes et al. 2016), but only in the bare parts (bill and legs) of zebra finches (Mundy et al. 2016). These differences between only two passerine species would suggest a large diversity in evolutionary constraints and strategies among species. 
720

\subsection{Dietary hydroxycarotenoids contributing to color}

Lutein and zeaxanthin supplementation attenuated the color decline observed throughout the breeding season in red-legged partridges (Alonso-Alvarez et al. 2008). Consistently with the highest rate of astaxanthin deposition in the ornaments, the ZeaLut treatment produced the reddest birds at the end of the study. We must note that statistical analyses testing the CAR effect only (Table 2) did not include data from birds treated with diquat at the last sampling event, which reduced the sample size by half. When color was tested by controlling the diquat effect, differences between the ZeaLut and LutZea group arose (Tables 3 and 4 and Fig. 5). The fact that ZeaLut birds were the reddest suggests that individuals could try to obtain the highest zeaxanthin amounts in the diet to generate ornaments with the highest astaxanthin levels (also García-de Blas et al. 2015). This scenario may support the involvement of an allocation trade-off between signaling and self-maintenance functions (Møller et al. 2000) based on a hypothetically scarce resource (i.e. zeaxanthin). On the other hand, the presence of papilioerythrinone in the same ornaments is probably due to the abundance of lutein in the diet and the contribution of papilioerythrinone to color (García-de Blas et al. 2013, 2014). However, astaxanthin is the most conjugated carotenoid, and hence, the reddest (and most abundant) pigment in red-legged partridge ornaments. Nonetheless, it has been shown that variability in papilioerythrinone levels in the red head traits can also contribute to explaining color variation, at least in a correlational sample of these birds (i.e. García-de Blas et al. 2013).

\subsection{Oxidative stress and carotenoids}

Results support that diquat indeed increased oxidative stress in our birds, although the challenge was apparently mild because no effect on body mass or egg production was detected. Diquat generates superoxide and hydrogen peroxide radicals and has been previously used in the same dose and species, reporting effects on blood antioxidant machinery and lipid peroxidation (Galván \& Alonso-Alvarez 2009; Alonso-Alvarez \& Galván 2010). In the present study, partridges treated with diquat showed weaker erythrocyte resistance to hemolysis when blood was exposed to another free radical source (AAPH). This measure has been associated with longterm (months or years) survival in other bird species (Alonso-Alvarez et al. 2006; Bize et al. 
749 2014). Moreover, diquat-treated females, but not males, showed higher levels of oxidative 750 damage in plasma lipids. Independently of diquat treatment, females allocated lower carotenoid

751

752

753

754

755

756

757

758

759

760

761

762

763

764

765

766

767

768

769

770

771

772

773

774

775

776

777

778

779 and tocopherol (i.e. antioxidants) amounts to ornaments than males (sex factor at $P<0.05$ in most models), suggesting a higher investment in other reproductive traits (e.g. egg yolk). Female birds could be more sensitive to oxidative damage during reproduction due to the costs associated with antioxidant allocation to eggs (e.g. Williams 2005). Accordingly, female redlegged partridges producing eggs with higher hatching success (probably linked to antioxidant content; McGraw et al. 2005) endured higher lipid peroxidation in erythrocytes (i.e. AlonsoAlvarez et al. 2010). Similarly, diquat-treated females, but not males, showed higher lipid peroxidation in the liver than controls, but only among birds that did not receive carotenoid supplements. In fact, LutZea and Ast females treated with diquat even showed a decline in liver MDA values compared to controls of the same group (Fig. 10). This may support the antioxidant role of xanthophylls involved in coloration, at least for females. This role has been questioned repeatedly, at least for avian species (Hartley \& Kennedy 2004; Costantini \& Møller 2008; Isaksson \& Andersson 2008; but see Simons et al. 2012).

Finally, results from circulating hydrosoluble antioxidants (PLAOX) were less consistent, showing declines in response to diquat in some carotenoid groups only, and depending on the sex (Fig. 10). Moreover, independently of diquat effects, higher PLAOX levels in Ast and LutZea birds of both sexes compared to controls were found (Fig. 3). In contrast, PLAOX did not increase in ZeaLut partridges. The antioxidant power of each pigment is linked to the number of conjugated double bonds: 13, 11 and 10 for astaxanthin, zeaxanthin, and lutein, respectively (Britton 1995, 2009; Martínez et al. 2008). Therefore, an increase in PLAOX among ZeaLut birds was predictable. Nonetheless, we must consider that PLAOX mostly assesses the presence of hydro-, but not lipid-soluble antioxidants (Miller et al. 1993; Cohen et al. 2007). Thus, a higher PLAOX may also be due to a compensatory mobilization of other antioxidants (e.g. vitamin C) to fight off a challenge of some type (Costantini et al. 2010). This view particularly agrees with the highest PLAOX values in Ast birds. These animals did not show astaxanthin in plasma and even experienced lower plasma lutein, zeaxanthin and tocopherol levels than controls (above). Similarly, Ast birds did not show astaxanthin in the liver, but accumulated large amounts of vitamin A in this organ, perhaps to protect the liver from some toxic insult (Garcíade Blas et al. 2015). Anyway, we found only one study supporting this toxic effect, in which rats 
780 fed with astaxanthin endured an impairment of the liver enzymes involved in detoxification 781 (Ohno et al. 2011). In summary, if PLAOX did not exclusively reveal the antioxidant capacity of

782

783 circulating carotenoids, the lack of higher PLAOX values in ZeaLut birds could merely be due to other (hydrosoluble) antioxidants being not mobilized. Here the conclusion is that the antioxidant role of carotenoid cannot easily be addressed by PLAOX measures only.

\subsection{Oxidative stress and carotenoid biotransformation}

Although the proximate cost of ketocarotenoid-based signaling in red-legged birds may, at least partially, involve increased foraging effort to obtain large zeaxanthin amounts (above), the requirement of biotransformation to produce red traits provides another substrate for natural selection. Birds exposed to diquat generated redder bills, which contradicts the constraining impact of oxidative stress on health (e.g. Monaghan et al. 2009; Dowling \& Simmons 2009; Costantini 2014). The results may, instead, support some response (perhaps hormetic; e.g. Costantini et al. 2010) against a mild stressor, at least in terms of color expression, although the exact mechanism can only be deducted (see below).

We must anyway mention that, in contrast to our results, red-legged partridges exposed to the same diquat dose and duration in another experiment, but during the first weeks of life, produced paler red colors in adulthood (Alonso-Alvarez \& Galván 2011). We must nonetheless consider that adverse conditions during early periods of life are particularly damaging (Metcalfe \& Monaghan 2001). Young individuals may not have fully developed antioxidant machinery (Metcalfe \& Alonso-Alvarez 2010) to properly manage such an oxidative challenge. Here, pigment levels in partridge ornaments support the color findings. Carotenoid concentrations increased under diquat exposure. Interestingly, the increase in these tissues was detected for astaxanthin, but not papilioerythrinone.

We can provide two alternative or complementary proximate mechanisms to explain these findings. First, we may suggest that a large availability of superoxide and hydrogen peroxide (free radicals) derived from diquat redox cycling (Kotch \& Hill 2016) could favor those conditions required for oxygen addition to hydroxycarotenoids by the enzyme (i.e. more than dehydrogenation), and hence, a higher astaxanthin production. We must here remember that astaxanthin production from its substrate requires two oxygenation reactions, whereas 
809 papilioerythrinone would require one oxygenation but also a dehydrogenation (McGraw et al. 810 2006; LaFountain et al. 2013, García-de Blas et al, 2014). We must also consider that the 811 hypothesized oxygenase (above) should require oxygen, as well as $\mathrm{Fe}^{2+}$ cation and nicotinamide 812 adenine dinucleotide phosphate (NADPH; a reducing agent; Fraser et al. 1997; Schoefs et al. 813 2001). The second possibility would be that superoxide and hydrogen peroxide levels increased

814

815 816 817 818 819 820

821 822 823 824 825 826 by diquat could act as redox signals (e.g. Hurd \& Murphy 2009) promoting oxygenase (but not dehydrogenase) transcription as a defensive or hormetic mechanism that would ultimately lead to carotenoid biotransformation. The two recent and simultaneously published articles describing the candidate oxygenase for converting yellow to red carotenoids in birds (Lopes et al. 2016; Mundy et al. 2016) show that the enzyme (i.e CYP2J19) is part of the well-known P450 cytochrome, which is involved in many detoxification reactions. Moreover, diquat has been shown to stimulate the transcription of similar oxygenase enzymes (i.e. heme-oxygenases) via redox signaling (i.e. via the Nuclear factor [erythroid-derived 2]-like 2 [Nrf2]; e.g. Black et al. 2008; Sun et al. 2011; Wilmes et al. 2011). We may here argue that high superoxide or hydrogen peroxide radicals produced by natural processes (e.g. exercise, flying effort; Costantini et al. 2012; Jenni-Eiermann et al. 2014) could activate a similar redox mechanism favoring oxygenase activity, which could explain why wild partridges are redder compared to captive birds whose flying capacity is restrained (García-de Blas et al. 2015).

Biotransformation due to oxidative stress, however, seems to be higher among birds with the highest availability of the main ketocarotenoid precursor; that is, ZeaLut birds (see in the eye ring; though $P=0.057$; Fig. 6). This again supports the importance of acquiring enough quantity of specific carotenoids with the diet in a sexual signaling context (i.e. Hill 1994; but see Hill 2011). Nevertheless, the clearest effect was found in diquat-treated birds that did not receive any carotenoid supplementation (Fig. 6). The effect in these two CAR groups would agree with bill color findings (Fig. 2SM), although the interaction was non-significant. The diquat effect on non-supplemented birds could be due to better zeaxanthin availability in the blood (Fig. 8) and liver (Fig 9) in this group. Higher circulating levels of zeaxanthin could be a consequence of an active mobilization from stores (liver) and/or better intestinal absorption, both for combating oxidative stress (e.g. Alonso-Alvarez et al. 2008; McClean et al. 2011; but see Isaksson \& Andersson 2008). Recent works suggest that xanthophyll absorption in the intestinal mucosa can be actively regulated by specific protein scavenger receptors such as the class B member 1 (SR- 
840 B1; Hill \& Johnson 2012; Sato et al. 2012). How diquat may have favored such receptors can 841 only be speculated, but we could again consider its potential influence on different redox 842 signaling pathways (above; also e.g. Cristóvão et al. 2009; Koch \& Hill 2016).

In any event, in order to test whether higher astaxanthin levels in ornaments are due to higher zeaxanthin availability (mobilization) in the body (i.e., not to higher biotransformation rates), we also added plasma or liver zeaxanthin levels as covariates in models testing bill and eye ring astaxanthin concentrations. As expected, a positive link between ornament astaxanthin and plasma zeaxanthin values was observed (also García-de Blas et al. 2015), but this did not change the CAR $\times$ diquat interaction or post hoc tests (always $P<0.05$ ). Moreover, diquat did not increase zeaxanthin values in internal tissues in the other group showing increased astaxanthin deposition in ornaments (ZeaLut; Fig. 8).

Other results may still support the availability of carotenoid precursors as a key factor favoring biotransformation. Diquat decreased tocopherol values in eye rings and bills among birds that did not receive supplemented carotenoids in food (Fig. 7). When tocopherol levels in these bare parts are not statistically controlled for as a covariate, differences in astaxanthin levels among the same control birds (Fig. 6) disappear (both traits: $P>0.60$ ), but in the eye rings of ZeaLut birds they become significant $(P=0.036)$. In other words, ZeaLut birds showed the highest astaxanthin levels in eye rings when exposed to diquat. This suggests that biotransformation can be even more stimulated by oxidative stress when the level of carotenoid precursors in the diet surpasses some threshold. When this is not the case, color is not impaired but tocopherol levels are probably consumed to control the challenge.

In summary, the overall results suggest that specific carotenoid precursors must be sufficiently available and that oxidative status must be well-adjusted in order to produce the most pigmented red ornaments. In agreement with this, redder integuments have also been observed in red-legged partridges exposed to other chemicals (i.e. pesticides and heavy metals) that induce oxidative stress (López-Antía et al. 2015a,b; Vallverdú-Coll et al., 2015) or in zebra finches enduring experimentally reduced antioxidant (glutathione) levels (Romero-Haro \& AlonsoAlvarez 2015). The findings support the view that oxidative stress is not only a constraint for the expression of optimal phenotypes, but that mild levels are involved in many functions (Jones 
869

870

871

872

873

874

875

876

877

878

879

880

881

882

883

884

885

886

887

888

889

890

891

892

893

894

895

896

2006; Metcalfe \& Alonso-Alvarez 2010; Isaksson et al. 2011). Furthermore, the study supports claims from Hill and Johnson (2012 and Johnson and Hill 2013) hypothesizing that carotenoidbased traits could be signaling an individual's efficiency to manage oxidative stress. The results also validate the older Völker's ideas suggesting that a good oxidative metabolism is necessary to biotransform carotenoids used in red coloration, which could explain why birds whose flying capacity was restrained by captivity became paler (i.e. Völker 1957). However, in contrast to the works of Hill and Johnson, our experiment also suggests the parallel involvement of a resource allocation trade-off because the body levels of substrate carotenoids influenced coloration and even the impact of oxidative stress on biotransformation. In eye rings, under oxidative stress exposure, birds receiving the highest zeaxanthin levels in the diet were also those producing the highest amounts of the main ketocarotenoid (astaxanthin). Finally, we cannot conclude this discussion without applying a life-history perspective. High levels of sexual signaling under high oxidative stress could constitute a sort of terminal investment, with individuals increasing their chances of reproducing when their perception of future survival becomes negative (Velando et al. 2007; Romero-Haro \& Alonso-Alvarez 2015).

\section{Acknowledgments}

We thank Ester Ferrero and Laura Ramirez for their help with the laboratory work and photographic analyses and Álvaro Galán for his help with the figures. We also thank Lorenzo Pérez-Rodríguez, Ana Angela Romero-Haro, Núria Vallverdú and Jaime Rodríguez their help during blood sampling and to Xurxo Piñeiro, Emiliano Sobrino, Fernando Dueñas and Luis Montó for partridge maintenance and Sarah Young for reviewing the English writing. We especially thank Prof Geoffrey Hill for his constructive review of the text.

\section{References}

Alonso-Alvarez C., Bertrand S., Devevey G., Gaillard M., Prost J., Faivre B., Sorci G. (2004) An experimental test of the dose-dependent effect of carotenoids and immune activation on sexual signals and antioxidant activity. The American Naturalist 164:651-659. 
897

906

907

908

909

910

911

912

913

914

915

916

917

918

919

920

921

922

923

924

925

926

927

928

929

930

931

932

Alonso-Alvarez C., Bertrand S., Devevey G., Prost J., Faivre B., Chastel O., Sorci G. (2006) An experimental manipulation of life-history trajectories and resistance to oxidative stress. Evolution, 60(9):1913-1924.

Alonso-Alvarez C., Pérez-Rodríguez L., Mateo R., Chastel O., Viñuela J. (2008) The oxidation handicap hypothesis and the carotenoid allocation trade-off. Journal of Evolutionary Biology, 21:1789-1797.

Alonso-Alvarez C., Pérez-Rodríguez L., García J.T., Viñuela J., Mateo R. (2010) Age and breeding effort as sources of individual variability in oxidative stress markers in a bird species. Physiological and Biochemical Zoology 83:110-118.

Alonso-Alvarez C., Galván I. (2011) Free radical exposure during development creates paler carotenoid-based ornaments: a possible interaction in the expression of black and red traits. PLoS One 6, e19403.

Alonso-Alvarez C., Pérez-Rodríguez L., Ferrero M.E., Garcia-de Blas E., Casas F., Mougeot F. (2012) Adjustment of female reproductive investment according to male carotenoid-based ornamentation in a gallinaceous bird. Behavioral Ecology and Sociobiology 66:731-742.

Andersson M. (1994) Sexual selection. Princeton University Press, New Jersey.

Bize P., Cotting S., Devevey G., van Rooyen J., Lalubin F., Glaizot O., Christe P. (2014) Senescence in cell oxidative status in two bird species with contrasting life expectancy. Oecologia 174:1097-1105.

Blache D., Prost M. (1992) Free radical attack: biological test for human resistance capability. A Lunar-Based Chemical Analysis Laboratory (eds C.Ponnamperuma \& C.W.Gehrke), pp. 8298. Deepak A, Hampton, VA.

Blem C.R. (2000) Energy Balance. In: G. Causey Whittow (Ed), Sturkie's Avian physiology. Fifth edition, Academic Press, San Diego, California, USA, pp 327-341.

Blount J.D., Metcalfe N.B., Birkhead T.R, Surai P.F. (2003) Carotenoid modulation of immune function and sexual attractiveness in zebra finches. Science 300:125-127.

Bradbury J.W., Vehrenkamp S.L. (1998) Principles of animal communication. Sunderland, MA: Sinauer.

Britton G. (1995) Structure and properties of carotenoids in relation to function. The FASEB Journal. 1551-1558.

Britton G., Liaaen-Jensen S., Pfander H. (2009) Carotenoids Volume 5: Nutrition and Health, Birkhäuser Verlag Basel Switzerland.

Brush A.H., Power D.M. (1976) House finch pigmentation: Carotenoid metabolism and effect of diet. The Auk 93:725-739.

Brush A.H. (1990) Metabolism of carotenoid pigments in birds. The FASEB Journal 4:29692977. 
933

934

935

936

937

938

939

940

941

942

943

944

945

946

Burton G.W. (1989) Antioxidant action of carotenoids. Journal of Nutrition 119(1):109-111.

Canene-Adams K., Erdman Jr J.W. (2009) Absorption, transport, distribution in tissues and bioavailability in Carotenoids vol 5 Nutrition and Health, Pp:115-148.

Catoni C., Peters A., Schaefer M. (2008) Life-history trade-offs are influenced by the diversity, availability and interactions of dietary antioxidants. Animal Behaviour 76:1107-1119.

Cohen A., Klasing K., Ricklefs R. (2007) Measuring circulating antioxidants in wild birds. Comparative Biochemistry and Physiology B 147, 110-121.

Costantini D., Møller A.P. (2008) Carotenoids are minor antioxidants for birds. Functional Ecology 22:367-370.

Costantini D., Mirzai N., Metcalfe N.B. (2012) An automated system to control and manipulate the flight activity of captive birds. Behavioral Ecology and Sociobiology 66: 1195-1199.

Costantini D., Metcalfe N.B., Monaghan P. (2010) Ecological processes in a hormetic framework. Ecology Letters. 13:1435-1447.

Costantini D. (2014) Oxidative Stress and Hormesis in Evolutionary Ecology and Physiology. A Marriage Between Mechanistic and Evolutionary Approaches. Springer.

Cristóvão AC., Choi D.H., Baltazar G., Beal M.F., Kim Y.-S. (2009) The role of NADPH oxidase 1-derived reactive oxygen species in paraquat-mediated dopaminergic cell death. Antioxidant \& Redox Signaling 11: 2105-2118.

Darwin C. (1871) The Descent of Man and Selection in Relation to Sex, John Murray, London.

Dowling D.K., Simmons L.W. (2009) Reactive oxygen species as universal constraints in lifehistory evolution. Proceedings of the Royal Society B 276:1737-1745.

del Val E., Senar J.C., Garrido-Fernández J., Jarén M., Borràs A., Cabrera J., Negro, J.J. (2009a). The liver but not the skin is the site for conversion of a red carotenoid in a passerine bird. Naturwissenschaften 96:797-801.

del Val E., Senar J.C., Garrido-Fernández J., Jarén M., Borràs A., Cabrera J., Negro, J.J. (2009b). Hepatic conversion of red carotenoids in passerine birds. Naturwissenschaften 96:989-991.

El-Agamey A., McGarvey D.J. (2008) Carotenoid Radicals and Radical Ions, in Carotenoids Volume 4: Natural Functions Ed Britton G., Liaaen-Jensen S., Pfander H. Birkhäuser Verlag.

Endler J.A. (1980) Natural selection on color patterns in Poecilia reticulata. Evolution 34: 7691.

Endler J.A. (1983) Natural and sexual selection on colour patterns in poeciliid fishes. Environmental Biology of Fishes 9: 173-190.

Fraser P.D., Miura Y., Misawa N. (1997) In Vitro Characterization of Astaxanthin Biosynthetic Enzymes. Biochemistry 272:6128-6135. 
967

968

969

970

971

972

973

974

975

976

977

978

979

980

981

982

983

984

985

986

987

988

989

990

991

992

993

994

995

996

997

998

999

1000

1001

1002

Foley J.D., Van Dam A. (1984) Fundamentals of Interactive Computer Graphics. AddisonWesley, Reading, MA.

Fox D.L., McBeth J.W. (1970) Some dietary carotenoids and blood carotenoid levels in flamingos. Comparative Biochemistry and Physiology 34:707-713.

Furr H.C., Clark R.M. (1997) Intestinal absorption and tissue distribution of carotenoids. Nutritional Biochemistry 8:364-377.

Fussell K.C., Udasin R.G., Gray J.P., Mishin V., Smith P.J.S., Heck D.E., Laskin J.D. (2011) Redox cycling and increased oxygen utilization contribute to diquat-induced oxidative stress and cytotoxicity in Chinese hamster ovary cells overexpressing NADPH-cytochrome P450 reductase. Free Radical Biology Medicine 50:874-882.

Galvan I., Alonso-Alvarez C. (2009) The expression of melanin-based plumage is separately modulated by exogenous oxidative stress and a melanocortin. Proceedings of the Royal Society B 276:3089-3097.

García-de Blas E., Mateo R., Viñuela J., Alonso-Alvarez C. (2011) Identification of carotenoid pigments and their fatty acid esters in an avian integument combining HPLC-DAD and LCMS analyses. Journal of Chromatography B 879:341-348.

García-de Blas E., Mateo R., Viñuela J., Pérez-Rodríguez L., Alonso-Alvarez C. (2013) Free and esterified carotenoids in ornaments of an avian species: the relationship to color expression and sources of variability. Physiological and Biochemical Zoology 86:483-498.

García-de Blas, E., Mateo, R., Guzmán Bernardo, F.J., Rodríguez Martín-Doimeadios, R.C., Alonso-Alvarez, C. (2014) Astaxanthin and papilioerythrinone in the skin of birds: A chromatic convergence of two metabolic routes with different precursors? Naturwissenschaften. 101:407-416.

García-de Blas, E., Mateo, R., Alonso-Alvarez, C. (2015) Accumulation of dietary carotenoids, retinoids and tocopherol in the internal tissues of a bird: a hypothesis for the cost of producing colored ornaments. Oecologia 177:259-271.

Getty T. (2006). Sexually selected signals are not similar to sports handicaps. Trends in Ecology \& Evolution 21: 83-88.

Girard A., Madani S., El Boustani E.S., Belleville J., Prost J. (2005) Changes in lipid metabolism and antioxidant defense status in spontaneously hypertensive rats and Wistar rats fed a diet enriched with fructose and saturated fatty acids. Nutrition 21:240-248.

Giraudeau M., Sweazea K., Butler M.W., McGraw K.J. (2013) Effects of carotenoid and vitamin E supplementation on oxidative stress and plumage coloration in house finches (Haemorhous mexicanus) Comparative Biochemistry and Physiology A 166:406-413.

Godin J.G.J., McDonough H.E. (2003) Predator preference for brightly colored males in the guppy: a viability cost for a sexually selected trait. Behavioral Ecology 14:194-200 
1003 Grafen A. (1990) Biological signals as handicaps. Journal of Theoretical Biology 144:517-546.

1004 Griffiths R., Double M.C., Orr K., Dawson R.J.G. (1998) A DNA test to sex most birds. 1005 Molecular Ecology 7:1071-1075.

1006 Halliwell B., Gutteridge J.M.C. (2007) Free Radicals in Biology and Medicine. Oxford: Oxford 1007 University Press.

1008 1009

1010

1011

1012

1013

1014

1015

1016

1017

1018

1019

1020

1021

1022

1023

1024

1025

1026

1027

1028

1029

1030

1031

1032

1033

1034

1035

Hasson O. (1997) Towards a general model of biological signaling. Journal of Theoretical Biology, 185:139-156.

Hata M., Hata M. (1972) Carotenoid pigments in goldfish. V. Conversion of zeaxanthin to astaxanthin Bulletin of the Japanese Society of Fisheries Science 38:339-343

Hill G.E. (1990) Female house finches prefer colorful males: Sexual selection for a conditiondependent trait. Animal Behaviour 40:563-570.

Hill G.E. (1994) Trait elaboration via adaptive mate choice: sexual conflict in the evolution of signals of male quality. Ethology, Ecology and Evolution 6:351-370.

Hill G. E. (2002) Red bird in brown bag. Oxford University Press, Oxford.

Hill G.E. (2006) Environmental regulation of ornamental coloration In: Bird Coloration I: Mechanisms and measurements (Hill, G. E. \& McGraw, K. J. eds.). Harvard University Press, Cambridge, MA.

Hill G.E. (2011) Condition-dependent traits as signals of the functionality of vital cellular processes. Ecology Letters 14:625-634.

Hill G.E., Johnson J.D. (2012) The vitamin A-redox hypothesis: a biochemical basis for honest signaling via carotenoid pigmentation. American Naturalist 180:E127-E150.

Hörak P., Saks L., Zilmer M., Karu U., Zilmer K. (2007) Do dietary antioxidants alleviate the cost of immune activation? An experiment with greenfinches. American Naturalist 170:625635.

Hurd T.R., Murphy M.P. (2009) Biological systems relevant for redox signaling and control. Pages 13-45 In Redox signaling and regulation in biology and medicine. C. Jacob, and P. G., Winyard eds. Wiley-VCH, Weinheim.

Isaksson C., Andersson S. (2008) Oxidative stress does not influence carotenoid mobilization and plumage pigmentation. Proceedings of the Royal Society B 275:309-314.

Isaksson C., Sheldon B.C., Uller T. (2011) The challenges of integrating oxidative stress into life history biology. Bioscience. 60:194-202.

Jenni-Eiermann S., Jenni L., Smith S., Costantini, D. (2014) Oxidative stress in endurance flight: an unconsidered factor in bird migration. Plos One 9: e97650. 
1036

1037

1038

1039

1040

1041

1042

1043

1044

1045

1046

1047

1048

1049

1050

1051

1052

1053

1054

1055

1056

1057

1058

1059

1060

1061

1062

1063

1064

1065

1066

1067

1068

1069

1070

1071

Johnson J.D., Hill G.E. (2013) Is carotenoid ornamentation linked to the inner mitochondrial membrane potential? A hypothesis for the maintenance of signal honesty. Biochimie 95:436444.

Jones D.P. (2006) Redefining oxidative stress. Antioxidants \& Redox Signaling. 8:1865-1879.

Koch R.E. \& Hill G.E. (2016) An assessment of techniques to manipulate oxidative stress in animals. Functional Ecology, in press. DOI: 10.1111/1365-2435.12664.

Koch R.E., Wilson A.E, Hill, G.E. (2016) The importance of carotenoid dose in supplementation studies with songbirds. Physiological and Biochemical Zoology 89:61-71.

Kodric-Brown A. (1985) Female preference and sexual selection for male coloration in the guppy (Poecilia reticulata). Behavioral Ecology and Sociobiology 17:199-205.

LaFountain A.M., Frank H.A., Prum R.O. (2013) Carotenoids from crimson and maroon plumages of Old World orioles (Oriolidae). Archives of Biochemistry and Biophysics 539:126-132.

Lesgards J.F., Durand P., Lassarre M., Stocker P., Lesgards G., Lanteaume A., Prost M., Lehucher-Michel M.P. (2002) Assessment of lifestyle effects on the overall antioxidant capacity of healthy subjects. Environmental Health Perspectives 110:479-487.

Littell R.C., Milliken G.A., Stroup W.W., Wolfinger R.D., Schabenberger O. (2006) SAS for mixed models. 2nd ed. SAS Institute, Cary, NC.

Lopes R.J., Johnson, J.D., Toomey M.B., Ferreira M.S., Araújo P.M., Melo-Ferreira J., Andersson L., Hill G.E., Corbo J.C., Carneiro M. (2016) Genetic basis for red coloration in birds report genetic basis for red coloration in birds. Current Biology, in press: DOI: 10.1016/j.cub.2016.03.076.

Lopez-Antia, A., Ortiz-Santaliestra, M.E., García-de Blas, E., Camarero, P.R., Mougeot, F., Mateo, R. (2015a). Adverse effects of thiram treated seed ingestion on the reproductive performance and the offspring immune function of the red-legged partridge. Environmental Toxicology and Chemistry 34:1320-1329.

Lopez-Antia, A., Ortiz-Santaliestra, M.E., Mougeot, F., Mateo, R. (2015b). Imidacloprid-treated seed ingestion has lethal effect on adult partridges and reduces both breeding investment and offspring immunity. Environmental Research 136: 97-107.

Lozano G. A. (1994) Carotenoids, parasites, and sexual selection. Oikos 70: 309-311.

Martínez A., Rodríguez-Gironés M.A., Barbosa A., Costas M. (2008) Donator acceptor map for carotenoids, melatonin and vitamins. The Journal of Physical Chemistry A 112:9037-9042.

Maynard Smith J. Harper D. (2003) Animal Signals. Oxford University Press.

Metcalfe N.B., Alonso-Alvarez C. (2010) Oxidative stress as a life-history constraint: the role of reactive oxygen species in shaping phenotypes from conception to death. Functional Ecology 24:984-996. 
1072 1073

1074

1075

1076

1077

1078

1079

1080

1081

1082

1083

1084

1085

1086

1087

1088

1089

1090

1091

1092

1093

1094

1095

1096

1097

1098

1099

1100

1101

1102

1103

1104

1105

1106

1107

McGraw K.J. (2004) Colorful songbirds metabolize carotenoids at the integument. Journal of Avian Biology 35:471-476.

McGraw K.J., Hill G.E. (2001) Carotenoid access and intraspecific variation in plumage pigmentation in male American Goldfinches (Carduelis tristis) and Northern Cardinals (Cardinalis cardinalis). Functional Ecology 15:732-739.

McGraw K.J., Gregory A.J. (2004) Carotenoid pigments in male American goldfinches: what is the optimal biochemical strategy for becoming colourful? Biological Journal of the Linnean Society. 83:273-280.

McGraw K.J., Hill G.E., Navara K.J., Parker R.S. (2004) Differential accumulation and pigmenting ability of dietary carotenoids in colorful finches. Physiological and Biochemical Zoology 77:484-491.

McGraw K.J., Adkins-Regan E., Parker R.S. (2005) Maternally derived carotenoid pigments affect offspring survival, sex ratio, and sexual attractiveness in a colorful songbird. Naturwissenschaften 92:375-380.

McGraw K.J. (2006) Mechanics of carotenoid-based coloration. In: Bird Coloration I: Mechanisms and measurements (Hill, G. E. \& McGraw, K. J. eds.). Harvard University Press, Cambridge, MA.

McGraw K.J. \& Parker R.S. (2006) A novel lipoprotein-mediated mechanism controlling sexual attractiveness in a colorful songbird. Physiology \& Behaviour 87: 103-108.

McGraw K.J. (2009) Identifying anatomical sites of carotenoid metabolism in birds. Naturwissenschaften 96:987-988.

McClean C.M., Clegg M., Shafat A., Murphy M.H., Trinick T., Duly E., McLaughlin J., Fogarty M., Davison G.W. (2011) The impact of acute moderate intensity exercise on arterial regional stiffness, lipid peroxidation, and antioxidant status in healthy males. Research in Sports Medicine 19:1-13.

Metcalfe N.B., Monaghan P. (2001) Compensation for a bad start: grow now, pay later? Trends in Ecology \& Evolution.16:254-260.

Miller N.J., Sampson J., Candeias L.P., Bramley P.M., Rice-Evans C.A. (1996) Antioxidant activities of carotenes and xanthophylls. FEBS Letter 384:240-242.

Møller A.P., Biard C., Blount J.D., Houston D.C., Ninni P., Saino N., Surai P.F. (2000) Carotenoid-dependent signals: Indicators of foraging efficiency, immunocompetence or detoxification ability? Avian and Poultry Biology Reviews 11:137-159.

Monaghan P., Metcalfe N.B., Torres R. (2009) Oxidative stress as a mediator of life history trade-offs: mechanisms, measurements, and interpretation. Ecology Letters 12:75-92.

Mortensen A., Skibsted L.H., Truscott T.G. (2001) The interaction of dietary carotenoids with radical species Archives of Biochemistry and Biophysics 385:13-19. 
1108

1109

1110

1111

1112

1113

1114

1115

1116

1117

1118

1119

1120

1121

1122

1123

1124

1125

1126

1127

1128

1129

1130

1131

1132

1133

1134

1135

1136

1137

1138

1139

1140

1141

1142

Mougeot F., Pérez-Rodríguez L., Sumozas N., Terraube J. (2009) Parasites, condition, immune responsiveness and carotenoid-based ornamentation in male red-legged partridge Alectoris rufa. Journal of Avian Biology 40:67-74.

Mundy N.I., Stapley J., Bennison C., Tucker R., Twyman H., Kim K.-W., Burke T., Birkhead T.R., Andersson S., Slate J. (2016) Red carotenoid coloration in the zebra finch is controlled by a cytochrome p450 gene cluster. Current Biology, in press. DOI: 10.1016/j.cub.2016.04.047.

Negro J.J., Garrido-Fernandez J. (2000) Astaxanthin is the major carotenoid in tissues of White storks (Ciconia ciconia) feeding on introduced crayfish (Procambarus clarkii). Comparative Biochemistry and Physiology B 126:347-352.

Ohkubo M., Tsushima M., Maoka T., Matsuno T. (1999) Carotenoids and their metabolism in the goldfish Carassius auratus (Hibuna). Comparative Biochemistry and Physiology B 124:333-340.

Ohno M., Darwish W.S., Ikenaka Y., Miki W., Ishizuka M. (2011) Astaxanthin can alter CYP1A-dependent activities via two different mechanisms: induction of protein expression and inhibition of NADPH P450 reductase dependent electron transfer. Food and chemical toxicology. 49:1285-1291.

Panfili G., Fratianni A., Irano M. (2004) Improved normal-phase high-performance liquid chromatography procedure for the determination of carotenoids in cereals. Journal of Agricultural and Food Chemistry 52: 6373-6377.

Pérez-Rodríguez L. (2008) Carotenoid-based ornamentation as a dynamic but consistent individual trait. Behavioral Ecology and Sociobiology 62:995-1005.

Pérez-Rodríguez L., Viñuela J. (2008) Carotenoid-based bill and eye ring coloration as honest signals of condition: an experimental test in the red-legged-partridge (Alectoris rufa). Naturwissenschaften 95:821-830.

Pérez-Rodríguez L., Mougeot F., Alonso-Alvarez C., Blas J., Viñuela J., Bortolotti G.R. (2008) Cell-mediated immune activation rapidly decreases plasma carotenoids but does not affect oxidative stress in red-legged partridges (Alectoris rufa). The Journal of Experimental Biology 211:2155-2161.

Pérez-Rodríguez L. (2009) Carotenoids in evolutionary ecology: re-evaluating the antioxidant role. BioEssays 31:1116-1126.

Pérez-Rodríguez L., Mougeot F., Alonso-Alvarez C. (2010) Carotenoid-based coloration predicts resistance to oxidative damage during an immune challenge. Journal of Experimental Biology 213:1685-1690.

Pietsch W. (2005) Agglomeration in Industry, Vol 1. Wiley-VCH-Verlag. 
1143

1144

1145

1146

1147

1148

1149

1150

1151

1152

1153

1154

1155

1156

1157

1158

1159

1160

1161

1162

1163

1164

1165

1166

1167

1168

1169

1170

1171

1172

1173

1174

1175

1176

1177

Rodríguez-Estival J., Martínez-Haro M., Martín-Hernando M.P., Mateo R. (2010) Sub-chronic effects of nitrate in drinking water on red-legged partridge (Alectoris rufa): Oxidative stress and T-cell mediated immune function. Environmental Research 110:169-175.

Rojas Wahl R.U., Liansheng Z., Madison S.A., DePinto R.L., Shay B.J. (1998) Mechanistic studies on the decomposition of water soluble azo-radical-initiators. Journal of the Chemical Society, Perkin Transactions 2:2009-2018.

Romero-Haro A., Alonso-Alvarez C. (2014) Covariation in oxidative stress markers in the blood of nestling and adult birds. Physiological and Biochemical Zoology 87:353-362.

Romero-Haro A., Canelo, T., Alonso-Alvarez C. (2015) Early development conditions and the oxidative cost of social context in adulthood: an experimental study in birds. Frontiers in Ecology and Evolution 3:35. doi: 10.3389/fevo.2015.00035

Romero-Haro A., Alonso-Alvarez C. (2015) The level of an intracellular antioxidant during development determines the adult phenotype in a bird species: a potential organizer role for glutathione. American Naturalist 185:390-405.

Saks L., Mcgraw K.J., Hõrak P. (2003) How feather colour reflects its carotenoid content. Functional Ecology 17:555-561

SAS Institute (2001) SAS/STAT software: changes and enhancements, version 8.2. SAS, Cary, $\mathrm{NC}$.

SatoY., Suzuki R., Kobayashi M., Itagaki S., Hirano T., Noda T., Mizuno S., Sugawara M., Iseki, K. (2012) Involvement of cholesterol membrane transporter Niemann-Pick C1-like 1 in the intestinal absorption of lutein. Journal of Pharmacy and Pharmaceutical Sciences 15:256 -264 .

Schoefs B., Rmiki N.E., Rachadi J., Lemoine Y. (2001) Astaxanthin accumulation in Haematococcus requires a cytochrome P450 hydroxylase and an active synthesis of fatty acids. FEBS Letters 500:125-128.

Sewalk, C. J., Brewer, G. L. \& Hoffman, D. J. (2001) Effects of diquat, an aquatic herbicide, on the development of mallard embryos. Journal of Toxicology and Environmental Health A 62:33-45.

Simons M.J.P., Cohen A.A., Verhulst S. (2012) What does carotenoid-dependent coloration tell? Plasma carotenoid level signals immunocompetence and oxidative stress state in birds - a meta-analysis. PlosOne 7:e43088.

Stahl W., Sies H. (2003) Antioxidant activity of carotenoids. Molecular Aspects of Medicine $24: 345-351$.

Stahl W., Sies H. (2005) Bioactivity and protective effects of natural carotenoids. Biochimica et Biophysica Acta 1740:101- 107. 
1178 Sorci G., Faivre B. (2009) Inflammation and oxidative stress in vertebrate host-parasite systems.

1179

1180

1181

1182

1183

1184

1185

1186

1187

1188

1189

1190

1191

1192

1193

1194

1195

1196

1197

1198

1199

1200

1201

1202

1203

1204

1205

1206

1207

1208

1209

1210

1211

1212

\section{Philosophical Transactions of the Royal Society B 364:71-83.}

Stirnemann I., Johnston G., Rich B., Robertson J. Kleindorfer S. (2009) Phytohaemagglutinin (PHA) response and bill-hue wavelength increase with carotenoid supplementation in Diamond Firetails (Stagonopleura guttata). Emu 109:344-351.

Stradi R. (1998) The Colour of Flight: Carotenoids in Bird Plumage. Solei Gruppo Editoriale Informatico, Milan.

Stradi R., Pini E., Celentano, G. (2001) Carotenoids in bird plumage: the complement of red pigments in the plumage of wild and captive bullfinch (Pyrrhula pyrrhula). Comparative Biochemistry and Physiology B 128:529-535.

Surai P.F., Speake B., Wood N., Blount J.D., Bortolotti G., Sparks N.H.C. (2001) Carotenoid discrimination by the avian embryo: a lesson from wild birds. Comparative Biochemistry and Physiology B 128:743-750.

Surai P.F. (2012) The antioxidant properties of canthaxanthin and its potential effects in the poultry eggs and on embryonic development of the chick. Part 1. World's Poultry Science Journal 68:465-476.

Tyssandier V., Cardinault N., Caris-Veyrat C., Amiot M.J., Grolier P., Bouteloup C., AzaisBraesco V., Borel P. (2002) Vegetable-borne lutein, lycopene, and $\beta$-carotene compete for incorporation into chylomicrons, with no adverse effect on the medium-term (3-wk) plasma status of carotenoids in humans. The American Journal of Clinical Nutrition 75:526-34.

Toomey M.B., McGraw K.J. (2010) The effects of dietary carotenoid intake on carotenoid accumulation in the retina of a wild bird, the house finch (Carpodacus mexicanus). Archives of Biochemistry and Biophysics 504:161-168.

Toomey M.B., McGraw K.J. (2011) The effects of dietary carotenoid supplementation and retinal carotenoid accumulation on vision-mediated foraging in the house finch. PLosOne 6:e21653.

Toomey M.B., McGraw K.J. (2012) Mate choice for a male carotenoid-based ornament is linked to female dietary carotenoid intake and accumulation. BMC Evolutionary Biology 12:3.

Vallverdú-Coll, N., Ortiz-Santaliestra, M.E., Mougeot, F., Vidal, D., Mateo, R. (2015). Sublethal $\mathrm{Pb}$ exposure produces season-dependent effects on immune response, oxidative balance and investment in carotenoid-based coloration in red-legged partridges. Environmental Science and Technology 49:3839-3850.

van den Berg H. (1999) Carotenoid interactions. Nutrition Reviews 57:1-10.

van Noordwijk A.J., de Jong G. (1986) Acquisition and allocation of resources: their influence on variation in life history tactics. American Naturalist 128:137 - 142. 
1213 Velando, A., Drummond, H., Torres, R. (2006) Senescent birds redouble reproductive effort 1214 when ill: confirmation of the terminal investment hypothesis. Proceedings of the Royal 1215 Society B 273:1443-1448.

1216 Völker O. (1957) Die experimentelle rotfärbung des Gefieders beim Fichtenkreuzschnabel 1217 (Loxia curvirostra). Journal of Ornithology 98:210-214.

1218 von Schantz T., Bensch S., Grahn M., Hasselquist D., Wittzell H. (1999) Good genes, oxidative 1219 stress and condition-dependent sexual signals. Proceedings of the Royal Society B 266:1-12.

Williams T.D. (2005) Mechanisms Underlying the Costs of Egg Production. BioScience. 55:3948.

Xu J., Sun S., Wei W., Fu J., Qi W., Manchester L.C., Tan D.-X., Reiter, R.J. (2007). Melatonin reduces mortality and oxidatively mediated hepatic and renal damage due to diquat treatment. Journal of Pineal Research 42, 166-171.

Zahavi A. (1975) Mate selection-selection for a handicap. Journal of Theoretical Biology $53: 205-214$.

Zeman, M., Herichová, I., Navarová, J., Gressnerová, S. \& Skrobánek, P. (2005) Melatonin interacts with effects of the herbicide diquat on selected physiological traits during ontogeny of Japanese quail. Biologia 60 (Suppl. 17):61-64.

1230 
1231 Table 1: Composition of a sample of each different type of food used in the experiment. For the 1232 names of the diets see section 2.1.

\begin{tabular}{|c|c|c|c|c|c|c|}
\hline Name diet & Lutein & Zeaxanthin & Astaxanthin & Total carotenoids & Retinol & Tocopherol \\
\hline Control & 1.33 & 0.69 & 0 & 1.96 & 2.5 & 8.3 \\
\hline LutZea & 24.77 & 9.32 & 0 & 34.09 & 3.5 & 10.9 \\
\hline ZeaLut & 17.64 & 18.6 & 0 & 36.24 & 10.4 & 15.1 \\
\hline Ast & 5.3 & 4.8 & 22.87 & 32.97 & 14.4 & 18.5 \\
\hline
\end{tabular}


1235 Table 2: Mixed models testing the interaction between carotenoid treatment and time. The reported tests 1236 are the best fitted models with an interaction at $P<0.10$, or instead, when it is removed at higher $P$ 1237 values by following a backward-step wise procedure (see Methods).

\begin{tabular}{|c|c|c|c|c|c|c|}
\hline $\begin{array}{c}\text { Dependent } \\
\text { variable }\end{array}$ & Terms in the model & Slope & $S E$ & $F$ & $d f$ & $P$ \\
\hline \multirow{7}{*}{ Eye rings redness } & Carotenoid & & & 10.22 & 3,167 & $<0.001$ \\
\hline & Sex & & & 3.97 & 1,167 & 0.048 \\
\hline & Time & & & 5.43 & 2,237 & 0.005 \\
\hline & Carotenoid $\mathrm{x}$ time & & & 2.65 & 6,237 & 0.017 \\
\hline & Eggs & -0.001 & 0.001 & 5.05 & 1,237 & 0.026 \\
\hline & Total brightness & -0.0001 & 0.0001 & 18.05 & 1,237 & $<0.001$ \\
\hline & Plasma tocopherol & 0.026 & 0.009 & 7.98 & 1,237 & 0.005 \\
\hline \multirow{6}{*}{ Bill redness } & Carotenoid & & & 6.58 & 3,168 & $<0.001$ \\
\hline & Time & & & 8.64 & 3,235 & $<0.001$ \\
\hline & Carotenoid $\mathrm{x}$ time & & & 1.96 & 6,235 & 0.072 \\
\hline & Eggs & -0.001 & 0.001 & 5.87 & 1,235 & 0.016 \\
\hline & Total brightness & -0.0002 & 0.00002 & 63.68 & 1,235 & $<0.001$ \\
\hline & Plasma tocopherol & 0.033 & 0.011 & 9.23 & 1,235 & 0.003 \\
\hline \multirow{9}{*}{ Legs redness } & Carotenoid & & & 6.04 & 3,167 & $<0.001$ \\
\hline & Sex & & & 17.6 & 1,167 & $<0.001$ \\
\hline & Time & & & 12.44 & 2,227 & $<0.001$ \\
\hline & Sex $x$ time & & & 1.36 & 2,227 & 0.258 \\
\hline & Carotenoid $\mathrm{x}$ time & & & 0.63 & 6,227 & 0.703 \\
\hline & Eggs & -0.025 & 0.022 & 1.28 & 1,227 & 0.259 \\
\hline & Red chip & 1.251 & 0.274 & 20.85 & 1,227 & $<0.001$ \\
\hline & Plasma tocopherol & 1.129 & 0.467 & 5.84 & 1,227 & 0.017 \\
\hline & Plasma retinol & -1.854 & 1.147 & 2.61 & 1,227 & 0.108 \\
\hline \multirow{8}{*}{ Plasma lutein } & Carotenoid & & & 105.1 & 3,164 & $<0.001$ \\
\hline & Sex & & & 54.22 & 1,164 & $<0.001$ \\
\hline & Time & & & 69.61 & 2,237 & $<0.001$ \\
\hline & Sex x carotenoid & & & 5.22 & 3,164 & 0.002 \\
\hline & Carotenoid $\mathrm{x}$ time & & & 36.81 & 6,237 & $<0.001$ \\
\hline & Plasma tocopherol & 0.456 & 0.026 & 313.86 & 1,237 & $<0.001$ \\
\hline & Plasma retinol & 0.168 & 0.065 & 6.74 & 1,237 & 0.01 \\
\hline & Eggs & -0.004 & 0.001 & 8.57 & 1,237 & 0.004 \\
\hline \multirow{6}{*}{ Plasma zeaxanthin } & Carotenoid & & & 309.6 & 3,164 & $<0.001$ \\
\hline & Sex & & & 47.35 & 1,164 & $<0.001$ \\
\hline & Time & & & 73.54 & 2,235 & $<0.001$ \\
\hline & Carotenoid $\mathrm{x}$ time & & & 95.93 & 6,235 & $<0.001$ \\
\hline & Sex $\mathrm{x}$ carotenoid & & & 3.68 & 3,164 & 0.013 \\
\hline & Sex $x$ time & & & 4.4 & 2,235 & 0.013 \\
\hline
\end{tabular}




\begin{tabular}{|c|c|c|c|c|c|c|}
\hline & Plasma tocopherol & 0.379 & 0.026 & 216.34 & 1,235 & $<0.001$ \\
\hline & Plasma retinol & 0.188 & 0.064 & 8.72 & 1,235 & 0.004 \\
\hline & Eggs & -0.006 & 0.001 & 20.9 & 1,235 & $<0.001$ \\
\hline \multirow{7}{*}{ Plasma tocopherol } & Carotenoid & & & 2.61 & 3,167 & 0.053 \\
\hline & Sex & & & 2.56 & 1,167 & 0.112 \\
\hline & Time & & & 117.68 & 2,236 & $<0.001$ \\
\hline & Carotenoid $\mathrm{x}$ time & & & 2.63 & 6,236 & 0.017 \\
\hline & Sex $\mathrm{x}$ time & & & 4.89 & 2,236 & 0.008 \\
\hline & Plasma retinol & 0.548 & 0.122 & 20.25 & 1,236 & $<0.001$ \\
\hline & Eggs & -0.009 & 0.002 & 14.94 & 1,236 & $<0.001$ \\
\hline \multirow{5}{*}{ Plasma retinol } & Carotenoid & & & 2.11 & 3,168 & 0.101 \\
\hline & Time & & & 36.06 & 2,238 & $<0.001$ \\
\hline & Carotenoid $\mathrm{x}$ time & & & 1.01 & 6,238 & 0.421 \\
\hline & Plasma tocopherol & 0.0852 & 0.019 & 20.8 & 1,238 & $<0.001$ \\
\hline & Eggs & -0.002 & 0.001 & 5.14 & 1,238 & 0.024 \\
\hline \multirow{6}{*}{$\begin{array}{c}U A \& A L B- \\
\text { corrected PLAOX }\end{array}$} & Carotenoid & & & 7.19 & 3,164 & $<0.001$ \\
\hline & Time & & & 0.38 & 2,187 & 0.686 \\
\hline & Carotenoid $\mathrm{x}$ time & & & 2.57 & 6,187 & 0.021 \\
\hline & Uric acid & 0.768 & 0.053 & 214 & 1,187 & $<0.001$ \\
\hline & Albumin & -0.498 & 0.112 & 19.99 & 1,187 & $<0.001$ \\
\hline & Plasma retinol & 0.228 & 0.098 & 5.17 & 1,187 & 0.024 \\
\hline \multirow{10}{*}{$\begin{array}{c}\text { Plasma TRG- } \\
\text { corrected } M D A\end{array}$} & Carotenoid & & & 1.05 & 3,164 & 0.371 \\
\hline & Sex & & & 0.29 & 1,164 & 0.593 \\
\hline & Time & & & 14.43 & 2,228 & $<0.001$ \\
\hline & Carotenoid $\mathrm{x}$ time & & & 0.71 & 6,228 & 0.645 \\
\hline & Sex x carotenoid & & & 1.8 & 3,164 & 0.149 \\
\hline & Sex $x$ time & & & 0.78 & 2,228 & 0.46 \\
\hline & Plasma tocopherol & -0.04 & 0.045 & 0.81 & 1,228 & 0.37 \\
\hline & Plasma retinol & -0.089 & 0.108 & 0.67 & 1,228 & 0.413 \\
\hline & Plasma triglycerides & 0.298 & 0.031 & 90.13 & 1,228 & $<0.001$ \\
\hline & Eggs & 0.001 & 0.002 & 0.37 & 1,228 & 0.543 \\
\hline \multirow{8}{*}{$\begin{array}{l}\text { Resistance to } \\
\text { oxidative stress } \\
\text { in erythrocytes }\end{array}$} & Carotenoid & & & 1.48 & 3,163 & 0.223 \\
\hline & Sex & & & 1.3 & 1,163 & 0.256 \\
\hline & Time & & & 1.7 & 2,203 & 0.185 \\
\hline & Carotenoid $\mathrm{x}$ time & & & 0.69 & 6,203 & 0.657 \\
\hline & Sex x carotenoid & & & 0.59 & 3,163 & 0.619 \\
\hline & Plasma retinol & -20.202 & 8.811 & 5.26 & 1,203 & 0.023 \\
\hline & Eggs & -0.339 & 0.18 & 3.55 & 1,203 & 0.061 \\
\hline & Lag time & -0.122 & 0.021 & 35.9 & 1,203 & $<0.001$ \\
\hline
\end{tabular}


1241 Table 3. Mixed models testing how the exposure to oxidative stress (diquat) interacted with the dietary 1242 carotenoid treatment at the end of the experiment. The level of each dependent variable in the sampling 1243 event precedent to the diquat exposure is included as a covariate for color and blood variables. The 1244 models describe the backward step (using the $P=0.10$ threshold) previous to remove the diquat $x$ CAR 1245 interaction (i.e. when it was non-significant; Methods).

\begin{tabular}{|c|c|c|c|c|c|c|}
\hline Dependent variable & Terms in the model & Slope & $S E$ & $F$ & $d f$ & $P$ \\
\hline \multirow{10}{*}{ Eye rings redness } & Carotenoid & & & 24.93 & 3,147 & $<0.001$ \\
\hline & Diquat & & & 0.03 & 1,146 & 0.859 \\
\hline & Sex & & & 0.8 & 1,146 & 0.373 \\
\hline & Carotenoid $x$ Diquat & & & 1.38 & 3,146 & 0.252 \\
\hline & Sex x Diquat & & & 3.21 & 1,146 & 0.075 \\
\hline & Total brightness & -0.00004 & 0.00002 & 6.25 & 1,147 & 0.014 \\
\hline & Eye ring redness in day 48 & 0.291 & 0.064 & 20.95 & 1,147 & $<0.001$ \\
\hline & Liver vitamin A & 0.0004 & 0.0003 & 1.33 & 1,147 & 0.251 \\
\hline & Eye ring tocopherol & 0.025 & 0.012 & 4.43 & 1,146 & 0.037 \\
\hline & Eggs during diquat experiment & -0.002 & 0.0008 & 4.44 & 1,146 & 0.037 \\
\hline \multirow{9}{*}{ Bill redness } & Carotenoid & & & 17.19 & $3,83.2$ & $<0.001$ \\
\hline & Diquat & & & 4.23 & $1,76.6$ & 0.043 \\
\hline & Sex & & & 1.46 & $1,75.9$ & 0.231 \\
\hline & Carotenoid $\mathrm{x}$ Diquat & & & 1.03 & $3,74.3$ & 0.382 \\
\hline & Sex x Carotenoid & & & 1.34 & $3,69.7$ & 0.269 \\
\hline & Total brightness & -0.0001 & 0.00003 & 23.14 & 1,143 & $<0.001$ \\
\hline & Bill redness in day 48 & 0.151 & 0.056 & 7.4 & 1,134 & 0.007 \\
\hline & Bill tocopherol & 0.048 & 0.014 & 11.7 & 1,118 & $<0.001$ \\
\hline & Liver vitamin A & 0.001 & 0.0004 & 5.72 & 1,138 & 0.018 \\
\hline \multirow{12}{*}{ Leg redness } & Carotenoid & & & 10.55 & 3,136 & $<0.001$ \\
\hline & Diquat & & & 0.23 & 1,137 & 0.631 \\
\hline & Sex & & & 3.98 & 1,138 & 0.048 \\
\hline & Carotenoid x Diquat & & & 0.67 & 3,137 & 0.575 \\
\hline & Sex x Diquat & & & 0.33 & 1,137 & 0.567 \\
\hline & Sex x Carotenoid & & & 1.69 & 3,137 & 0.173 \\
\hline & Red chip & 1.018 & 0.221 & 21.28 & $1,28.8$ & $<0.001$ \\
\hline & Leg redness in day 48 & 0.594 & 0.065 & 82.46 & 1,137 & $<0.001$ \\
\hline & Leg tocopherol & 2.752 & 0.605 & 20.73 & 1,137 & $<0.001$ \\
\hline & Liver tocopherol & -1.469 & 0.544 & 7.28 & 1,138 & 0.008 \\
\hline & Liver vitamin A & -0.024 & 0.015 & 2.73 & 1,135 & 0.101 \\
\hline & Total number of eggs & -0.032 & 0.014 & 5.1 & 1,137 & 0.026 \\
\hline & \multicolumn{3}{|l|}{ Carotenoid } & 51.64 & 3,146 & $<0.001$ \\
\hline & \multicolumn{3}{|l|}{ Diquat } & 1.47 & 1,151 & 0.227 \\
\hline Total astaxanthin & \multicolumn{3}{|l|}{ Carrotenoid $\mathrm{x}$ Diquat } & 3.21 & 3,147 & 0.025 \\
\hline
\end{tabular}




\begin{tabular}{|c|c|c|c|c|c|c|}
\hline \multirow{4}{*}{ in the eye rings } & Sex & & & 17.4 & 1,148 & $<0.001$ \\
\hline & Sex x Carotenoid & & & 3.21 & 3,146 & 0.025 \\
\hline & Tocopherol in the eye rings & 0.674 & 0.06 & 125.22 & 1,149 & $<0.001$ \\
\hline & Total number of eggs & -0.004 & 0.002 & 6.54 & 1,145 & 0.012 \\
\hline \multirow{10}{*}{$\begin{array}{c}\text { Total papilioerythrinone } \\
\text { in the eye rings }\end{array}$} & Carotenoid & & & 19.9 & $3,88.3$ & $<0.001$ \\
\hline & Diquat & & & 0.55 & $1,80.1$ & 0.46 \\
\hline & Sex & & & 13.83 & $1,79.6$ & $<0.001$ \\
\hline & Carotenoid $\mathrm{x}$ Diquat & & & 0.33 & $3,77.4$ & 0.804 \\
\hline & Sex x Diquat & & & 1.74 & $1,81.8$ & 0.19 \\
\hline & Sex x Carotenoid & & & 3.71 & $3,79.5$ & 0.015 \\
\hline & Fat retinol & 0.032 & 0.031 & 1.04 & 1,136 & 0.309 \\
\hline & Plasma tocopherol & 0.3 & 0.182 & 2.71 & 1,140 & 0.102 \\
\hline & Tocopherol in the eye rings & 0.85 & 0.149 & 32.42 & 1,140 & $<0.001$ \\
\hline & Total number of eggs & -0.007 & 0.004 & 3.03 & $1,83.8$ & 0.086 \\
\hline \multirow{4}{*}{$\begin{array}{l}\text { Tocopherol } \\
\text { in the eye rings }\end{array}$} & Carotenoid & & & 3.64 & $3,71.7$ & 0.017 \\
\hline & Diquat & & & 1.22 & $1,75.7$ & 0.272 \\
\hline & Carotenoid x Diquat & & & 2.63 & $3,73.5$ & 0.056 \\
\hline & Total number of eggs & -0.006 & 0.002 & 8.96 & $1,71.1$ & 0.004 \\
\hline \multirow{6}{*}{$\begin{array}{l}\text { Total astaxanthin } \\
\text { in the bill }\end{array}$} & Carotenoid & & & 141.3 & 3,151 & $<0.001$ \\
\hline & Sex & & & 5.43 & 1,155 & 0.021 \\
\hline & Diquat & & & 4.68 & 1,157 & 0.032 \\
\hline & Carrotenoid x Diquat & & & 2.67 & 3,155 & 0.049 \\
\hline & Plasma tocopherol & 1.176 & 0.061 & 371.2 & 1,158 & $<0.001$ \\
\hline & Total number of eggs & -0.007 & 0.002 & 17.86 & 1,151 & $<0.001$ \\
\hline \multirow{7}{*}{$\begin{array}{c}\text { Total papilioerythrinone } \\
\text { in the bill }\end{array}$} & Carotenoid & & & 134.5 & $3,64.8$ & $<0.001$ \\
\hline & Diquat & & & 0.08 & $1,68.8$ & 0.774 \\
\hline & Sex & & & 2.66 & $1,75.8$ & 0.107 \\
\hline & Carotenoid x Diquat & & & 1.76 & 3,66 & 0.163 \\
\hline & Tocopherol in the bill & 1.536 & 0.133 & 133.35 & 1,134 & $<0.001$ \\
\hline & Plasma retinol & -9.373 & 4.689 & 4 & 1,140 & 0.048 \\
\hline & Total number of eggs & -0.009 & 0.003 & 9.17 & $1,73.4$ & 0.003 \\
\hline \multirow{5}{*}{$\begin{array}{c}\text { Tocopherol } \\
\text { in the bill }\end{array}$} & Carotenoid & & & 2.94 & 3,158 & 0.035 \\
\hline & Diquat & & & 3.91 & 1,162 & 0.05 \\
\hline & Carotenoid x Diquat & & & 3.09 & 3,160 & 0.029 \\
\hline & Sex & & & 5.6 & 1,161 & 0.019 \\
\hline & Total number of eggs & -0.007 & 0.002 & 9.66 & 1,159 & 0.002 \\
\hline \multirow{6}{*}{$\begin{array}{l}\text { Total astaxanthin } \\
\text { in the legs }\end{array}$} & Carotenoid & & & 7.36 & $3,92.1$ & $<0.001$ \\
\hline & Diquat & & & 0.13 & $1,78.8$ & 0.7168 \\
\hline & Sex & & & 2.98 & $1,86.9$ & 0.088 \\
\hline & Carotenoid x Diquat & & & 0.07 & 3,76 & 0.974 \\
\hline & Sex x Diquat & & & 0.14 & $1,76.6$ & 0.712 \\
\hline & Sex x Carotenoid & & & 0.56 & $3,74.3$ & 0.645 \\
\hline
\end{tabular}




\begin{tabular}{|c|c|c|c|c|c|c|}
\hline & Plasma tocopherol & 0.146 & 0.113 & 1.66 & 1,144 & 0.199 \\
\hline & Liver vitamin A & 0.004 & 0.002 & 3.32 & 1,133 & 0.071 \\
\hline & Fat retinol & -0.032 & 0.018 & 3.19 & 1,130 & 0.077 \\
\hline & Tocopherol in the legs & 0.526 & 0.097 & 29.25 & 1,141 & $<0.001$ \\
\hline & Total number of eggs & 0.003 & 0.002 & 1.37 & $1,87.5$ & 0.244 \\
\hline \multirow{8}{*}{$\begin{array}{c}\text { Total papilioerythrinone } \\
\text { in the legs }\end{array}$} & Carotenoid & & & 4.17 & $3,92.9$ & 0.008 \\
\hline & Diquat & & & 0.61 & $1,84.9$ & 0.436 \\
\hline & Sex & & & 6.93 & $1,91.3$ & 0.01 \\
\hline & Carotenoid $\mathrm{x}$ Diquat & & & 0.17 & $3,82.1$ & 0.919 \\
\hline & Sex x Diquat & & & 0.24 & $1,81.1$ & 0.627 \\
\hline & Sex x Carotenoid & & & 0.16 & $3,78.8$ & 0.919 \\
\hline & Tocopherol in the legs & 0.867 & 0.147 & 34.64 & 1,143 & $<0.001$ \\
\hline & Liver vitamin A & -0.003 & 0.004 & 0.49 & 1,144 & 0.484 \\
\hline \multirow{5}{*}{$\begin{array}{l}\text { Tocopherol } \\
\text { in the legs }\end{array}$} & Carotenoid & & & 4.09 & $3,82.2$ & 0.009 \\
\hline & Diquat & & & 2.4 & $1,83.8$ & 0.125 \\
\hline & Carotenoid x Diquat & & & 1.21 & $1,82.4$ & 0.3126 \\
\hline & Sex & & & 5.98 & 1.89 .5 & 0.016 \\
\hline & Total number of eggs & -0.004 & 0.002 & 4.41 & $1,82.1$ & 0.039 \\
\hline \multirow{6}{*}{ Plasma lutein } & Carotenoid & & & 151.01 & 3,149 & $<0.001$ \\
\hline & Diquat & & & 0.01 & 1,149 & 0.925 \\
\hline & Carotenoid $x$ Diquat & & & 2.84 & 3,149 & 0.04 \\
\hline & Lutein at day 48 & 0.446 & 0.062 & 51.81 & 1,149 & $<0.001$ \\
\hline & Plasma tocopherol & 0.479 & 0.0326 & 215.52 & 1,149 & $<0.001$ \\
\hline & Eggs during diquat experiment & -0.003 & 0.002 & 4.42 & 1,149 & 0.037 \\
\hline \multirow{8}{*}{ Plasma zeaxanthin } & Carotenoid & & & 321.37 & 3,146 & $<0.001$ \\
\hline & Diquat & & & 0.83 & 1,146 & 0.363 \\
\hline & Carotenoid $\mathrm{x}$ Diquat & & & 1.57 & 3,146 & 0.2 \\
\hline & Zeaxanthin at day 48 & 0.307 & 0.07 & 19.24 & 1,146 & $<0.001$ \\
\hline & Plasma tocopherol & 0.572 & 0.039 & 219.4 & 1,146 & $<0.001$ \\
\hline & Fat tocopherol & -0.037 & 0.013 & 8.24 & 1,146 & 0.005 \\
\hline & Liver vitamin A & 0.002 & 0.001 & 4.79 & 1,146 & 0.03 \\
\hline & Eggs during diquat experiment & -0.004 & 0.002 & 4.05 & 1,146 & 0.046 \\
\hline \multirow{10}{*}{ Plasma tocopherol } & Carotenoid & & & 5.26 & $3,95.1$ & 0.002 \\
\hline & Diquat & & & 2.72 & $1,82.3$ & 0.103 \\
\hline & Sex & & & 0.14 & $1,86.2$ & 0.71 \\
\hline & Carotenoid x Diquat & & & 0.7 & $3,79.3$ & 0.552 \\
\hline & Sex x Diquat & & & 0.7 & $1,82.7$ & 0.404 \\
\hline & Tocopherol at day 48 & 0.199 & 0.069 & 8.31 & 1,139 & 0.005 \\
\hline & Liver vitamin A & -0.004 & 0.002 & 3.99 & 1,134 & 0.048 \\
\hline & Fat retinol & 0.03 & 0.016 & 3.34 & 1,138 & 0.07 \\
\hline & Plasma retinol & 0.259 & 0.162 & 2.57 & 1,141 & 0.111 \\
\hline & Total number of eggs & -0.003 & 0.002 & 2.21 & $1,84.2$ & 0.141 \\
\hline
\end{tabular}




\begin{tabular}{|c|c|c|c|c|c|c|}
\hline \multirow{9}{*}{ Plasma retinol } & \multicolumn{3}{|l|}{ Carotenoid } & 1.36 & $3,80.5$ & 0.262 \\
\hline & \multicolumn{3}{|l|}{ Diquat } & 1.54 & $1,80.3$ & 0.218 \\
\hline & \multicolumn{3}{|l|}{ Sex } & 0.51 & $1,77.9$ & 0.476 \\
\hline & \multicolumn{3}{|l|}{ Carotenoid x Diquat } & 0.51 & $3,77.7$ & 0.678 \\
\hline & \multicolumn{3}{|l|}{ Sex x Diquat } & 0.31 & $1,78.7$ & 0.579 \\
\hline & \multicolumn{3}{|l|}{ Sex x Carotenoid } & 0.64 & $3,79.5$ & 0.589 \\
\hline & Retinol at day 48 & 33.86 & 4.27 & 62.89 & 1,134 & $<0.001$ \\
\hline & Plasma tocopherol & 5.209 & 1.95 & 7.13 & 1,140 & 0.009 \\
\hline & Eggs during diquat experiment & -0.258 & 0.095 & 7.34 & $1,73.6$ & 0.008 \\
\hline \multirow{5}{*}{ Liver lutein } & \multicolumn{3}{|l|}{ Carotenoid } & 128.63 & 3,157 & $<0.001$ \\
\hline & \multicolumn{3}{|l|}{ Diquat } & 0.06 & 1,157 & 0.811 \\
\hline & \multicolumn{3}{|l|}{ Carotenoid x Diquat } & 1.49 & 3,157 & 0.22 \\
\hline & Plasma tocopherol & 0.075 & 0.036 & 4.45 & 1,157 & 0.037 \\
\hline & Liver tocopherol & 0.263 & 0.028 & 85.5 & 1,157 & $<0.001$ \\
\hline \multirow{6}{*}{ Liver zeaxanthin } & \multicolumn{3}{|l|}{ Carotenoid } & 315.42 & 3,151 & $<0.001$ \\
\hline & \multicolumn{3}{|l|}{ Diquat } & 0 & 1,154 & 0.971 \\
\hline & \multicolumn{3}{|l|}{ Carotenoid x Diquat } & 3.06 & 3,151 & 0.03 \\
\hline & Plasma tocopherol & 0.1 & 0.046 & 4.69 & 1,151 & 0.031 \\
\hline & Liver tocopherol & 0.341 & 0.04 & 74.08 & $1,40.3$ & $<0.001$ \\
\hline & Plasma retinol & 0.003 & 0.001 & 3.6 & 1,153 & 0.06 \\
\hline \multirow{3}{*}{ Liver tocopherol } & \multicolumn{3}{|l|}{ Carotenoid } & 12.77 & 3,161 & $<0.001$ \\
\hline & \multicolumn{3}{|l|}{ Diquat } & 6.47 & 1,161 & 0.012 \\
\hline & \multicolumn{3}{|l|}{ Carotenoid x Diquat } & 2.76 & 3,161 & 0.044 \\
\hline \multirow{8}{*}{ Liver vitamin $A$} & \multicolumn{3}{|l|}{ Carotenoid } & 57.35 & 3,152 & $<0.001$ \\
\hline & \multicolumn{3}{|l|}{ Diquat } & 0.04 & 1,154 & 0.834 \\
\hline & \multicolumn{3}{|l|}{ Sex } & 22.3 & 1,154 & $<0.001$ \\
\hline & \multicolumn{3}{|l|}{ Carotenoid x Diquat } & 0.47 & 3,152 & 0.707 \\
\hline & \multicolumn{3}{|l|}{ Sex x Diquat } & 0.71 & 1,152 & 0.399 \\
\hline & Plasma tocopherol & -11.032 & 4.001 & 7.6 & 1,153 & 0.007 \\
\hline & Liver tocopherol & 10.309 & 3.538 & 8.49 & $1,55.8$ & 0.005 \\
\hline & Total number of eggs & -0.394 & 0.07 & 31.26 & 1,152 & $<0.001$ \\
\hline & Carotenoid & & & 12.87 & 3,147 & $<0.001$ \\
\hline & Diquat & & & 0.06 & 1,148 & 0.808 \\
\hline & Sex & & & 0.13 & 1,147 & 0.716 \\
\hline & Carotenoid x Diquat & & & 0.21 & 3,148 & 0.89 \\
\hline$F$ & Sex x Diquat & & & 0.19 & 1,147 & 0.662 \\
\hline F ar tuetn & Sex x Carotenoid & & & 1.26 & 3,147 & 0.292 \\
\hline & Fat tocopherol & 1.288 & 0.181 & 50.69 & 1,142 & $<0.001$ \\
\hline & Liver vitamin A & 0.022 & 0.01 & 4.62 & 1,147 & 0.033 \\
\hline & Plasma retinol & -0.039 & 0.016 & 5.77 & 1,147 & 0.018 \\
\hline & Fat retinol & 0.241 & 0.087 & 7.72 & 1,148 & 0.006 \\
\hline Fat zeaxanthin & Carotenoid & & & 46.74 & 3,148 & $<0.001$ \\
\hline
\end{tabular}




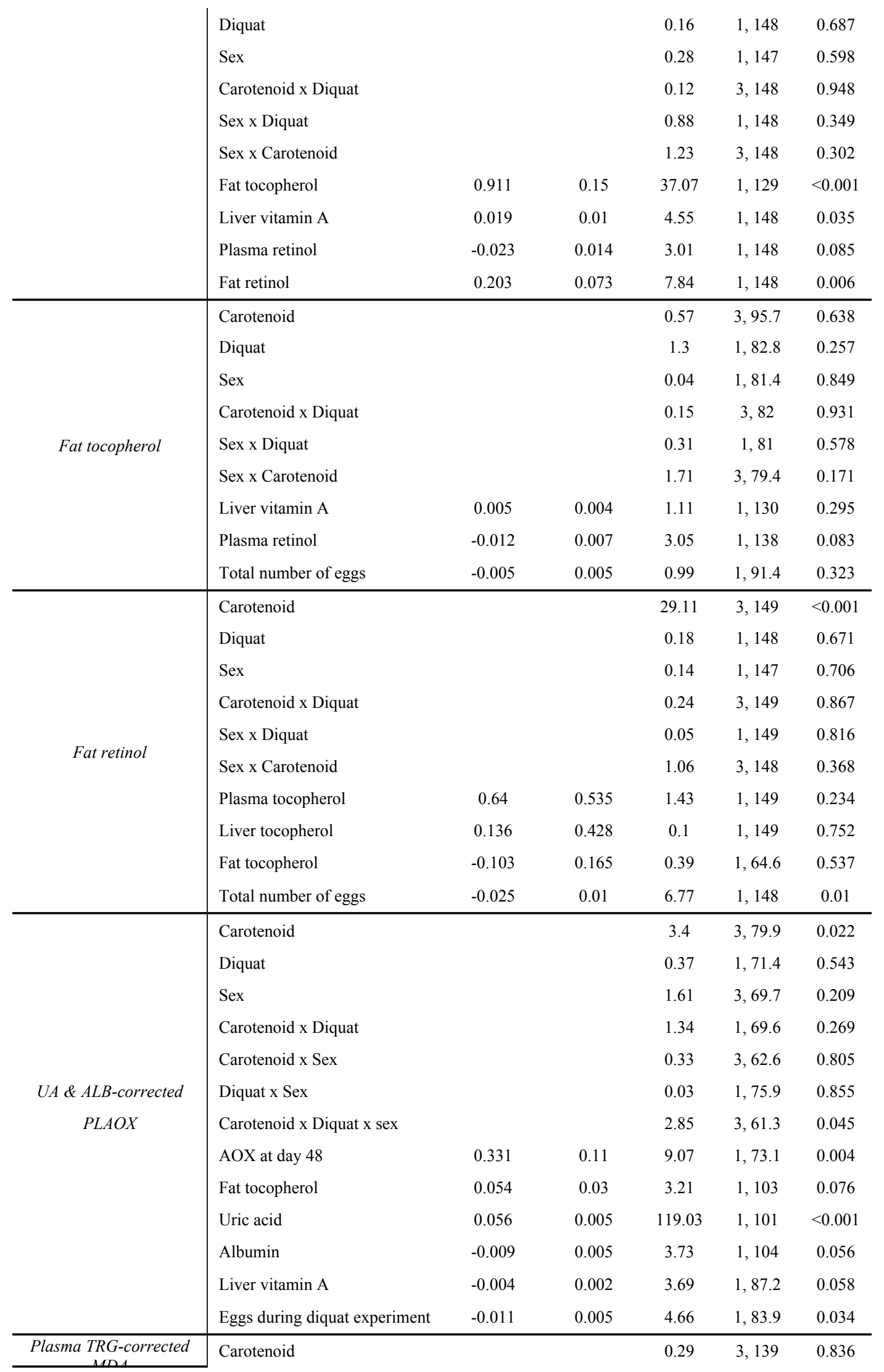




\begin{tabular}{|c|c|c|c|c|c|c|}
\hline & \multicolumn{3}{|l|}{ Diquat } & 6.84 & 1,139 & 0.009 \\
\hline & \multicolumn{3}{|l|}{ sex } & 4.8 & 1,140 & 0.03 \\
\hline & \multicolumn{3}{|l|}{ Carotenoid $x$ Diquat } & 0.86 & 3,139 & 0.466 \\
\hline & \multicolumn{3}{|l|}{ Diquat $x$ Sex } & 4.45 & 1,140 & 0.037 \\
\hline & $\begin{array}{l}\text { TRG-corrected MDA } \\
\text { at day } 48\end{array}$ & 2.419 & 0.745 & 10.48 & 1,139 & 0.002 \\
\hline & Triglycerides & 0.004 & 0.001 & 36.4 & 1,140 & $<0.001$ \\
\hline & Eggs during diquat experiment & 0.126 & 0.044 & 8.28 & 1,140 & 0.005 \\
\hline \multirow{9}{*}{ Liver $M D A$} & \multicolumn{3}{|l|}{ Carotenoid } & 1.27 & 3,88 & 0.289 \\
\hline & \multicolumn{3}{|l|}{ Diquat } & 0.2 & $1,77.4$ & 0.659 \\
\hline & \multicolumn{3}{|l|}{ Sex } & 22.76 & $1,80.4$ & $<0.001$ \\
\hline & \multicolumn{3}{|l|}{ Carotenoid x Diquat } & 1.96 & $3,76.7$ & 0.127 \\
\hline & \multicolumn{3}{|l|}{ Carotenoid x Sex } & 1.21 & 3,75 & 0.311 \\
\hline & \multicolumn{3}{|l|}{ Diquat $x$ Sex } & 0.15 & $1,75.4$ & 0.699 \\
\hline & \multicolumn{3}{|l|}{ Carotenoid x Diquat x sex } & 4.65 & 3,76 & 0.005 \\
\hline & Liver vitamin A & 0.0002 & 0.0001 & 7.07 & 1,138 & 0.009 \\
\hline & Plasma tocopherol & 0.0003 & 0.0001 & 3.73 & 1,139 & 0.055 \\
\hline \multirow{4}{*}{ Heart MDA } & \multicolumn{3}{|l|}{ Carotenoid } & 0.09 & 3,157 & 0.963 \\
\hline & \multicolumn{3}{|l|}{ Diquat } & 0.95 & 1,157 & 0.331 \\
\hline & \multicolumn{3}{|l|}{ Sex } & 2.75 & 1,157 & 0.099 \\
\hline & \multicolumn{3}{|l|}{ Carotenoid $\mathrm{x}$ Diquat } & 1.79 & 3,157 & 0.151 \\
\hline \multirow{4}{*}{$\begin{array}{l}\text { Erythrocyte resistance } \\
\text { to oxidative stress }\end{array}$} & \multicolumn{3}{|l|}{ Carotenoid } & 0.35 & $3,61.1$ & 0.793 \\
\hline & \multicolumn{3}{|l|}{ Diquat } & 5.66 & $1,61.1$ & 0.021 \\
\hline & \multicolumn{3}{|l|}{ Carotenoid x Diquat } & 2.27 & $3,61.4$ & 0.09 \\
\hline & Lag time & -0.229 & 0.035 & 44.06 & 1,121 & $<0.001$ \\
\hline
\end{tabular}


1250 Table 4. Best fitted models obtained when the diquat $x$ CAR interaction is removed at P>0.10 after a backward 1251 stepwise procedure (see Methods). Heart MDA and fat tocopherol did not maintained any term (all $\mathrm{P}>0.10)$.

\begin{tabular}{|c|c|c|c|c|c|c|}
\hline Dependent variable & Terms in the model & Slope & $S E$ & $F$ & $d f$ & $P$ \\
\hline \multirow{5}{*}{ Eye rings redness } & Carotenoid & & & 25.55 & 3,154 & $<0.001$ \\
\hline & Total brightness & -0.00004 & 0.00002 & 7.71 & 1,155 & 0.006 \\
\hline & Eye ring redness in day 48 & 0.286 & 0.064 & 19.99 & 1,155 & $<0.001$ \\
\hline & Eye ring tocopherol & 0.023 & 0.012 & 6.72 & 1,154 & 0.011 \\
\hline & $\begin{array}{l}\text { Eggs during diquat } \\
\text { experiment }\end{array}$ & -0.002 & 0.001 & 6.21 & 1,155 & 0.014 \\
\hline \multirow{6}{*}{ Bill redness } & Carotenoid & & & 16.22 & $3,85.7$ & $<0.001$ \\
\hline & Diquat & & & 4.46 & $1,77.9$ & 0.038 \\
\hline & Total brightness & -0.0001 & 0.00003 & 22.32 & 1,150 & $<0.001$ \\
\hline & Bill redness in day 48 & 0.163 & 0.054 & 9.1 & 1,141 & 0.003 \\
\hline & Bill tocopherol & 0.045 & 0.013 & 11.6 & 1,132 & $<0.001$ \\
\hline & Liver vitamin A & 0.0008 & 0.0004 & 4.26 & 1,141 & 0.041 \\
\hline \multirow{6}{*}{ Leg redness } & Carotenoid & & & 10.86 & $3,77.2$ & $<0.001$ \\
\hline & Sex & & & 2.86 & $1,80.3$ & 0.095 \\
\hline & Red chip & 1.035 & 0.217 & 22.83 & $1,27.4$ & $<0.001$ \\
\hline & Leg redness in day 48 & 0.58 & 0.064 & 81.19 & 1,147 & $<0.001$ \\
\hline & Leg tocopherol & 3.022 & 0.589 & 26.36 & 1,146 & $<0.001$ \\
\hline & Liver tocopherol & -1.78 & 0.523 & 11.59 & 1,147 & $<0.001$ \\
\hline \multirow{4}{*}{$\begin{array}{c}\text { Total } \\
\text { papilioerythrinone } \\
\text { in the eye rings }\end{array}$} & Carotenoid & & & 25.34 & 3,153 & $<0.001$ \\
\hline & Sex & & & 15.53 & 1,156 & $<0.001$ \\
\hline & Tocopherol in the eye ring & 0.953 & 0.14 & 46.43 & 1,158 & $<0.001$ \\
\hline & Eggs (total) & -0.009 & 0.004 & 5.43 & 1,153 & 0.021 \\
\hline \multirow{5}{*}{$\begin{array}{c}\text { Total papilioerythrinone } \\
\text { in the bill }\end{array}$} & Carotenoid & & & 131.19 & $3,68.3$ & $<0.001$ \\
\hline & Sex & & & 2.9 & $1,76.3$ & 0.092 \\
\hline & Tocopherol in the bill & 1.564 & 0.129 & 147.34 & 1,142 & $<0.001$ \\
\hline & Plasma retinol & -9.038 & 4.666 & 3.75 & 1,145 & 0.055 \\
\hline & Eggs (total) & -0.009 & 0.003 & 8.37 & $1,77.9$ & 0.005 \\
\hline \multirow{3}{*}{$\begin{array}{l}\text { Total astaxanthin } \\
\text { in the legs }\end{array}$} & Carotenoid & & & 9.4 & $3,77.9$ & $<0.001$ \\
\hline & Sex & & & 10.56 & 1,87 & 0.002 \\
\hline & Tocopherol in the legs & 0.564 & 0.081 & 48.28 & 1,159 & $<0.001$ \\
\hline \multirow{3}{*}{$\begin{array}{l}\text { Total papilioerythrinone in } \\
\text { the legs }\end{array}$} & Carotenoid & & & 5.24 & $3,84.2$ & 0.002 \\
\hline & Sex & & & 7.39 & $1,86.3$ & 0.008 \\
\hline & Tocopherol in the legs & 0.866 & 0.139 & 38.79 & 1,152 & $<0.001$ \\
\hline \multirow{3}{*}{ Tocopherol in the legs } & Carotenoid & & & 3.97 & $3,85.7$ & 0.011 \\
\hline & Sex & & & 5.74 & $1,89.2$ & 0.019 \\
\hline & Eggs (total) & -0.004 & 0.002 & 4.93 & $1,85.4$ & 0.029 \\
\hline \multirow{2}{*}{ Plasma zeaxanthin } & Carotenoid & & & 322.78 & 3,150 & $<0.001$ \\
\hline & Zeaxanthin in day 48 & 0.31 & 0.07 & 19.6 & 3,150 & $<0.001$ \\
\hline
\end{tabular}




\begin{tabular}{|c|c|c|c|c|c|c|}
\hline & Plasma tocopherol & 0.561 & 0.038 & 217.91 & 3,150 & $<0.001$ \\
\hline & Fat tocopherol & -0.038 & 0.013 & 8.72 & 3,150 & 0.004 \\
\hline & Liver vitamin A & 0.002 & 0.001 & 5.35 & 3,150 & 0.022 \\
\hline & $\begin{array}{l}\text { Eggs during diquat } \\
\text { experiment }\end{array}$ & -0.004 & 0.002 & 4.06 & 3,150 & 0.046 \\
\hline \multirow{5}{*}{ Plasma tocopherol } & Carotenoid & & & 5.78 & $3,98.2$ & 0.001 \\
\hline & Diquat & & & 4.26 & $1,86.9$ & 0.042 \\
\hline & Tocopherol in day 48 & 0.19 & 0.066 & 8.32 & 1,144 & 0.005 \\
\hline & Liver vitamin A & -0.003 & 0.001 & 2.89 & 1,147 & 0.091 \\
\hline & Fat retinol & 0.034 & 0.016 & 4.81 & 1,147 & 0.029 \\
\hline \multirow[b]{2}{*}{ Plasma retinol } & Plasma tocopherol & 5.608 & 2.058 & 7.43 & 1,153 & 0.007 \\
\hline & $\begin{array}{l}\text { Eggs during diquat } \\
\text { experiment }\end{array}$ & -0.278 & 0.112 & 6.18 & 1,78 & 0.015 \\
\hline \multirow{3}{*}{ Liver lutein } & Carotenoid & & & 130.26 & 3,161 & $<0.001$ \\
\hline & Plasma tocopherol & 0.071 & 0.035 & 3.98 & 1,161 & 0.048 \\
\hline & Liver tocopherol & 0.263 & 0.028 & 87 & 1,161 & $<0.001$ \\
\hline \multirow{5}{*}{ Liver vitamin $A$} & Carotenoid & & & 59.87 & 3,157 & $<0.001$ \\
\hline & Sex & & & 23.03 & 1,159 & $<0.001$ \\
\hline & Plasma tocopherol & -11.396 & 3.947 & 8.34 & 1,157 & 0.004 \\
\hline & Liver tocopherol & 9.738 & 3.418 & 8.12 & 1,58 & 0.006 \\
\hline & Total number of eggs & -0.396 & 0.069 & 32.78 & 1,157 & $<0.001$ \\
\hline \multirow{5}{*}{ Fat lutein } & Carotenoid & & & 13.3 & 3,156 & $<0.001$ \\
\hline & Fat tocopherol & 1.29 & 0.175 & 54.41 & 1,153 & $<0.001$ \\
\hline & Liver vitamin A & 0.02 & 0.01 & 4.42 & 1,157 & 0.037 \\
\hline & Plasma retinol & -0.036 & 0.016 & 5.34 & 1,156 & 0.022 \\
\hline & Fat retinol & 0.271 & 0.084 & 10.44 & 1,157 & 0.002 \\
\hline \multirow{4}{*}{ Fat zeaxanthin } & Carotenoid & & & 46.81 & 3,163 & $<0.001$ \\
\hline & Fat tocopherol & 0.952 & 0.143 & 44.45 & 1,146 & $<0.001$ \\
\hline & Liver vitamin A & 0.018 & 0.008 & 5.32 & 1,162 & 0.022 \\
\hline & Fat retinol & 0.208 & 0.069 & 9.03 & 1,163 & 0.003 \\
\hline \multirow{2}{*}{ Fat retinol } & Carotenoid & & & 35.37 & 3,167 & $<0.001$ \\
\hline & Total number of eggs & -0.026 & 0.01 & 8.62 & 1,165 & 0.004 \\
\hline \multirow{6}{*}{$\begin{array}{c}\text { Plasma TRG-corrected } \\
M D A\end{array}$} & Diquat & & & 7.04 & 1,145 & 0.009 \\
\hline & sex & & & 5.13 & 1,147 & 0.025 \\
\hline & Diquat $x$ Sex & & & 4.66 & 1,145 & 0.033 \\
\hline & $\begin{array}{c}\text { TRG-corrected MDA in } \\
\text { day } 48\end{array}$ & 2.366 & 0.739 & 10.26 & 1,144 & 0.002 \\
\hline & Triglycerides & 0.004 & 0.001 & 38.25 & 1,146 & $<0.001$ \\
\hline & $\begin{array}{l}\text { Eggs during diquat } \\
\text { experiment }\end{array}$ & 0.136 & 0.043 & 10.17 & 1,146 & 0.002 \\
\hline \multirow{2}{*}{$\begin{array}{l}\text { Resistance to oxidative } \\
\text { stress in erythrocytes }\end{array}$} & Diquat & & & 5.64 & $1,67.4$ & 0.02 \\
\hline & Lag time & -0.242 & 0.034 & 49.91 & 1,128 & $<0.001$ \\
\hline
\end{tabular}

